\title{
Edificações em alvenaria resistente na região metropolitana do Recife
}

Masonry buildings in the metropolitan region of Recife

\section{Romilde Almeida Oliveira \\ Fernando Artur Nogueira Silva \\ Carlos Welligton de Azevedo Pires Sobrinho Antônio Augusto Costa de Azevedo}

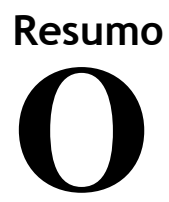

trabalho apresenta reflexões acerca das edificações em alvenaria resistente no Estado de Pernambuco. São abordados temas relativos às principais características dessa técnica construtiva bem como as peculiaridades que influenciam diretamente seu desempenho estrutural. Aspectos relacionados aos desabamentos que ocorreram nos últimos anos são igualmente abordados, acompanhados da indicação da causa da ruptura e do ano em que ocorreram. $\mathrm{O}$ artigo contempla, adicionalmente, uma extensa caracterização dos materiais e componentes utilizados em construções em alvenaria resistente na região, constituindo-se numa das mais abrangentes investigações sobre essa temática desenvolvida no país. Foi analisado experimentalmente o comportamento compressivo de blocos, prismas e miniparedes confeccionados com esses materiais que integram um sistema de vedação que tem sido utilizado com função estrutural frequentemente na região. Os resultados obtidos permitem identificar a contribuição das camadas de argamassa de revestimento na capacidade de carga dos elementos ensaiados. Diversos fatores que interferem nessa contribuição foram igualmente estudados. Ao final, expõe-se uma súmula dos resultados de todos os ensaios realizados que esclarecem de maneira detalhada as formas de ruptura observadas que se mostraram marcadamente frágeis, a exemplo do que ocorreu na maior parte dos acidentes com esse tipo de edificação na região.

Palavras-chaves: Alvenaria resistente. Desabamentos. Ensaios experimentais.

\section{Abstract}

Romilde Almeida Oliveira Universidade Católica de Pernambuco Recife - PE - Brasil

Fernando Artur Nogueira Silva Universidade Católica de Pernambuco Recife - PE - Brasil

Carlos Welligton de Azevedo Pires Sobrinho Instituto Tecnológico de Pernambuco Recife - PE - Brasil

Antônio Augusto Costa de Azevedo Universidade Católica de Pernambuco Recife - PE - Brasil

Recebido em 21/08/15 Aceito em 05/10/16
The paper discusses masonry buildings constructed in the state of Pernambuco, Brazil. Topics such as the main features of this construction technique and the peculiarities that affect its structural behaviour are discussed. Technical information about accidents occurred in recent years are also discussed, along with the historical records of the events, followed by indications of the causes for the collapse. Additionally, this paper presents an extensive characterisation of materials and components used in non-structural masonry constructions in the region, making it one of the most comprehensive research studies on this topic in Brazil. This study conducts an in-depth, numerical and experimental analysis of the behaviour of the compressive strength of blocks, prisms and mini-walls that are part of a non-load bearing system, which is often used in the region to carry loads above its own weight. The results obtained allowed to identify the contribution of several mortar rendering layers to the load capacity of the tested specimens. The factors that influenced the load capacity of the tested specimens are also discussed. Finally, a summary of the main results of all the tests performed is presented in order to provide a detailed explanation for the failures modes observed, which were always sudden and brittle, as was the case in most accidents that occurred with this type of building in the region.

Keywords: Masonry buildings. Accidents with masonry buildings. Experimental tests. 


\section{Introdução}

A ocorrência de diversos acidentes em edifícios construídos com alvenaria resistente na Região Metropolitana do Recife (RMR), caracterizada como edificações em alvenaria que utilizam blocos de vedação com finalidade estrutural, tem chamado a atenção da comunidade técnica regional e nacional para a necessidade de se estabelecer critérios de investigação, estudo e reabilitação, dentro de níveis de confiabilidade aceitáveis. Diversas manifestações patológicas têm sido observadas, já tendo ocorrido, em alguns casos, desmoronamentos com vítimas fatais. É importante registrar que o problema em discussão não se constitui numa exclusividade local, e é do conhecimento dos autores a existência de acidente com características similares em Maceió, AL, e manifestações patológicas da mesma natureza em prédio situado em Belo Horizonte, MG.

Números aproximados indicam que existe na RMR cerca de 6.000 edifícios residenciais executados em alvenaria resistente, que correspondem a 72.000 unidades habitacionais que abrigam perto de 250.000 pessoas - aproximadamente $7 \%$ da população da RMR. Os sinistros já ocorridos nos últimos anos conduzem a uma probabilidade de falha com valores superiores a 1:500, quando o aceitável socialmente é de, no máximo, 1:10.000. Doze desabamentos espontâneos já foram registrados, doze edifícios foram demolidos e cerca de 110 prédios se encontram interditados por não oferecerem condições de segurança para habitação (OLIVEIRA; SOBRINHO, 2006). O quadro instalado se constitui num grave problema social que exige intervenções firmes e urgentes para o seu enfrentamento.

Nesse tipo de edificação, geralmente se utilizam blocos cerâmicos vazados assentados com os furos na horizontal ou blocos de concreto, com baixa resistência à compressão $(2,5 \mathrm{MPa})$.

Essa prática construtiva teve importante impulso a partir do início da década de 1960 e seu sucesso deveu-se, em grande parte, ao menor custo em relação às obras com estrutura convencional de concreto armado, à rapidez na execução, à grande aplicabilidade e ao baixo custo dos blocos cerâmicos e de concreto produzidos no estado de Pernambuco, naquela ocasião (OLIVEIRA; SOBRINHO, 2006).

Um fato que concorreu diretamente para o surgimento desse processo foi a ausência de normas relativas à alvenaria estrutural no país e a incipiente presença de informações técnicas qualificadas sobre esse sistema construtivo nos currículos dos cursos de engenharia civil da região à época (OLIVEIRA; SILVA; SOBRINHO, 2008).

Com efeito, a norma referente a blocos de concreto é datada de 1983 e a de Procedimentos de Projeto e Construção de Alvenaria com Blocos de Concreto - a antiga NBR 10837, substituída pela NBR 15961 (ABNT, 2011a, 2011b), tem validade a partir de 1989. Para o caso de alvenaria estrutural com o emprego de blocos cerâmicos, a NBR 15812-1 só veio a ser editada em 2010.

Por outro lado, a busca pela minimização dos custos, a falta de controle de qualidade dos componentes e dos procedimentos construtivos, aliada à inexistência de normas técnicas específicas, vêm causando, ao longo dos últimos anos, uma série de manifestações patológicas e acidentes.

A frequência desses sinistros e a natureza brusca da ruptura, com colapso progressivo, têm gerado inquietação à comunidade técnica e, principalmente, aos moradores dessas edificações, que hoje vivem em sobressalto pela incerteza das condições de segurança estrutural de suas residências.

No que diz respeito às estratégias de recuperação desse tipo de edificação, são escassas as informações na literatura. Em nível nacional, destaca-se a pesquisa desenvolvida na Escola de Engenharia de São Carlos (EESC-USP), que investigou a contribuição do revestimento na resistência de prismas de alvenaria construídas com blocos de vedação (HANAI; OLIVEIRA, 2006; OLIVEIRA; HANAI, 2002). Em nível internacional a escassez de informações é similar e esse fato pode ser explicado pela falta de interesse científico em se estudar uma técnica construtiva que contempla uma contradição intrínseca: a utilização de blocos de vedação com função estrutural. Na prática local, o que tem sido observado é o emprego de soluções de recuperação fundamentadas em conhecimentos empíricos que carecem de reflexão mais aprofundada sobre sua eficácia e aplicabilidade (CAMPOS, 2006).

Nesse contexto, o presente trabalho apresenta resultados de pesquisas desenvolvidas no âmbito do Projeto Finep/Habitare, denominado Morear desenvolvimento de modelos para recuperação de edificações construídas em alvenaria resistente. $\mathrm{O}$ Projeto foi conduzido pela Universidade Católica de Pernambuco (Unicap), como entidade executora, pela Associação Instituto Tecnológico de Pernambuco (Itep), como proponente, pela Secretaria de Ciências, Tecnologia e Meio Ambiente (Sectma), como interveniente, e pela Universidade de Pernambuco (UPE) e 
Universidade Federal de Santa Catarina (UFSC) como coexecutoras.

\section{Características das edificaçoes construídas em alvenaria resistente}

A alvenaria resistente é uma técnica construtiva que se caracteriza pela utilização de unidades (cerâmicas ou de concreto) de vedação empregadas com finalidade estrutural, suportando cargas além do seu próprio peso.

As lajes das construções em alvenaria resistente são, na sua maioria, nervuradas, pré-moldadas com blocos cerâmicos ou de concreto e capeamento de concreto com cerca de $4 \mathrm{~cm}$ de espessura. Essas lajes são frequentemente assentadas diretamente sobre as paredes ou sobre cintas de concreto executadas no seu coroamento.

As fundações são geralmente construídas em alvenarias com $9 \mathrm{~cm}$ ou $19 \mathrm{~cm}$ de espessura, em continuidade às paredes da edificação, usualmente assentadas sobre sapatas corridas de concreto armado com seção tranversal em forma de $\mathrm{T}$ invertido ou sobre componentes de fundação prémoldados, assentados sobre camada de regularização de concreto.

Tem sido constatada a execução do piso do pavimento térreo da edificação em laje prémoldada, semelhante às empregadas nos demais pisos da edificação, em substituição ao preenchimento do espaço formado pelas paredes externas da fundação da obra com aterro compactado (caixão vazio na Figura 1).

Nesse tipo de edificação é frequente não se dispor cintas de concreto armado na interface fundaçãoparede de elevação ou mesmo nas interfaces parede-laje em cada pavimento, sendo também comum a ausência de vergas e contravergas nos vãos de aberturas de portas e janelas.

As paredes de elevação são construídas em alvenaria de blocos cerâmicos ou de concreto, com espessura média de $9 \mathrm{~cm}$, com juntas verticais descontínuas, assentadas com variados tipos de argamassas:

(a) argamassa de cimento, cal e areia;

(b) argamassa de cimento saibro e areia; e

(c) argamassa de cimento e areia.

Essa espessura das paredes é responsável, em grande parte, pela redução da já pequena capacidade de carga desses elementos resistentes devido à esbeltez. Para os valores de pé-direito usualmente empregados nesse tipo de construção, 2,60 m, tem-se uma esbeltez próxima de 30 , superior àquela admitida para construções em alvenaria estrutural, de 24

Geralmente, os revestimentos externos e internos das paredes da edificação são constituídos de argamassas mistas de cimento.

Figura 1 - Detalhe esquemático de uma edificação típica em alvenaria resistente

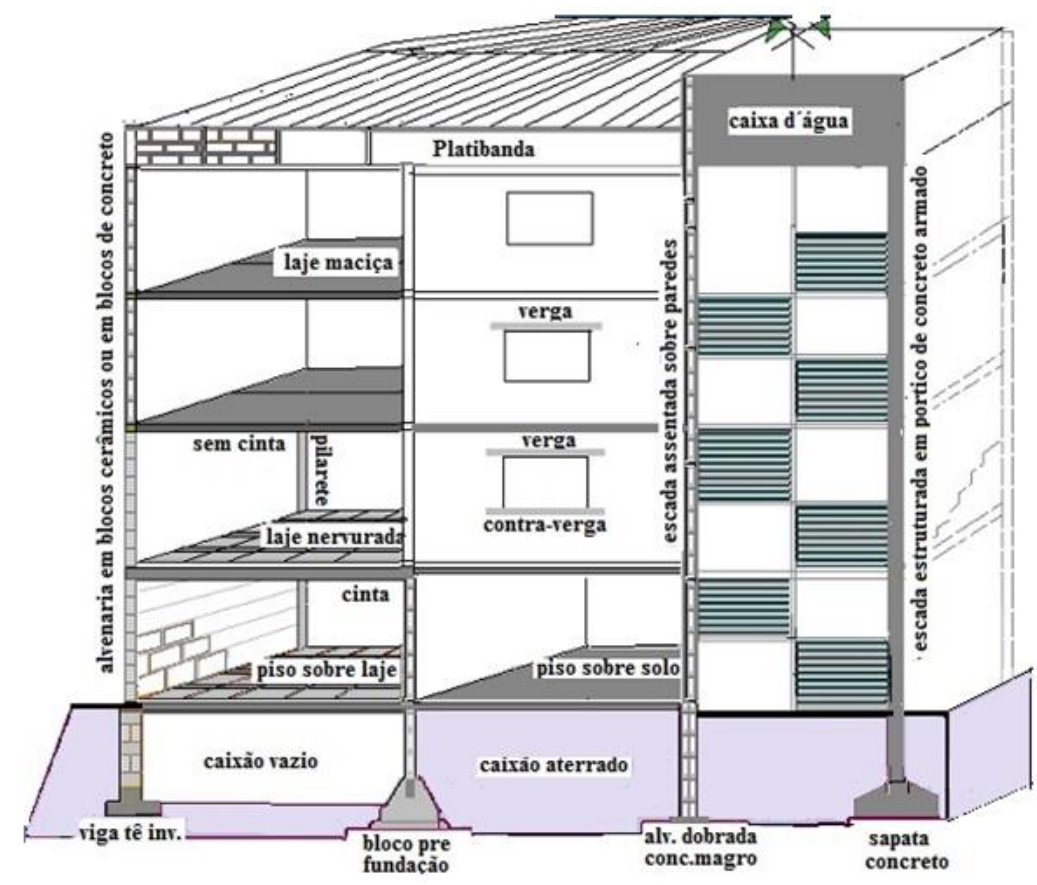


A caixa de escada, muitas vezes posicionada na parte central do bloco, é ordinariamente estruturada em pórtico de concreto armado que serve de suporte do reservatório de água superior. Em alguns casos, são observadas escadas apoiadas diretamente sobre as paredes da edificação.

A estrutura de telhado, na maioria das vezes em madeira, assenta-se sobre as paredes por meio de pilaretes ou barrotes, e a cobertura é executada com telhas de fibrocimento ou cerâmicas.

Os principais elementos carcacterísticos das construções em alvenaria resistente na região se acham representados na Figura 1, que representa uma ilustração de uma edificação típica onde essa técnica construtiva foi utilizada (SOBRINHO, 2007).

\section{Desabamentos mais significativos de edificações em alvenaria resistente no estado de Pernambuco}

A seguir serão apresentadas informações sobre os desabamentos mais significativos ocorridos com edificações em alvenaria resistente no Estado de Pernambuco.

A Figura 2, partes I e II, apresenta uma súmula dos acidentes já ocorridos na região com indicação do nome da edificação, uma foto representativa da ruptura, sua localização, as causas dos desabamentos e o ano em que ocorreram. Essas edificações são regionalmente conhecidas como prédios tipo caixão, numa alusão à sua geometria que se assemelha a uma grande caixa.

A descrição detalhada dos colapsos ocorridos encontram-se relatadas no livro intitulado Alvenaria resistente: uma investigação experimental e numérica sobre seu comportamento compressivo (OLIVEIRA; SILVA; SOBRINHO, 2011), editado a partir dos resultados da pesquisa realizada.

Mais recentemente, em maio de 2013, 14 blocos do Residencial Eldorado, localizado no Bairro do Arruda, em Recife, foram desocupados pela Secretaria-Executiva de Defesa Civil do Recife porque um dos seus blocos rompeu de maneira repentina a partir do esmagamento da alvenaria de blocos cerâmicos vazados existentes entre a viga de fundação e a laje do térreo da edificação.

Uma vez que os demais blocos exibiam características construtivas semelhantes ao que colapsou, houve uma desocupação total de todo o Residencial que atingiu um contingente de 224 famílias (cerca de 800 pessoas). A Figura 3 e a Figura 4 ilustram a situação encontrada nas paredes da edificação, após o colapso do Bloco A1.

Não houve vítimas nesse acidente, mas sua ocorrência indica que os problemas com os prédios caixão na região ainda se constituem numa situação que tem deixado em sobressalto seus moradores. Com efeito, outros acidentes podem ocorrer a qualquer momento porque as condições propícias para novos eventos ainda permanecem presentes e os riscos tendem a se acentuar com o natural envelhecimento dessas edificações.

\section{Programa experimental}

A fim de se avaliar o comportamento de elementos de alvenaria resistente, foram ensaiados blocos de concreto e blocos cerâmicos, prismas e miniparedes. Os prismas foram confeccionados e ensaiados no Laboratório de Materiais da Universidade Católica de Pernambuco e as miniparedes foram confeccionadas e ensaiadas no Laboratório de Tecnologia da Habitação do Instituto de Tecnologia de Pernambuco (Itep).

\section{Unidades: blocos de concreto e blocos cerâmicos}

Os blocos cerâmicos e de concreto utilizados nos ensaios foram do mesmo tipo daqueles que são empregados em construções de alvenaria resistente. As características dimensionais dos blocos foram obtidas por meio de ensaios de 60 (sessenta) blocos cerâmicos e 30 (trinta) blocos de concreto. A Tabela 1 sumariza os valores médios obtidos para os blocos cerâmicos e de concreto, respectivamente. Conforme se pode observar, principalmente a partir dos valores da resistência à compressão, os blocos de concreto ou cerâmico têm características compatíveis com elementos de vedação. 
Figura 2 - Dados dos principais colapsos ocorridos na RMR - Parte I

\begin{tabular}{|c|c|c|c|}
\hline $\begin{array}{c}\text { Nome de } \\
\text { edifício }\end{array}$ & Imagem da ruptura & Localização & Causas do colapso/ano \\
\hline $\begin{array}{c}\text { Residencial } \\
\text { Bosque das } \\
\text { Madeiras }\end{array}$ & & Recife & $\begin{array}{l}\text { Rasgos horizontais executados } \\
\text { ao longo de toda extensão de } \\
\text { uma parede divisória central } \\
\text { para instalação de } \\
\text { eletrodutos/1994 }\end{array}$ \\
\hline $\begin{array}{l}\text { Edifício } \\
\text { Aquarela }\end{array}$ & & $\begin{array}{l}\text { Jaboatão } \\
\text { dos } \\
\text { Guararapes }\end{array}$ & $\begin{array}{l}\text { Perda de resistência dos blocos } \\
\text { de fundação decorrente da } \\
\text { expansão por umidade/1997 }\end{array}$ \\
\hline $\begin{array}{c}\text { Edifício } \\
\text { Éricka }\end{array}$ & & Olinda & $\begin{array}{l}\text { Perda de resistência devido à } \\
\text { degradação produzida pela ação } \\
\text { continuada de íons de sulfatos } \\
\text { sobre os blocos de } \\
\text { concreto/1999 }\end{array}$ \\
\hline $\begin{array}{l}\text { Conjunto } \\
\text { Enseada de } \\
\text { Serrambi - } \\
\text { Bloco B }\end{array}$ & & Olinda & $\begin{array}{l}\text { Ruptura dos blocos cerâmicos } \\
\text { da fundação/1999 - (ocorerram } \\
\text { sete vítimas fatais) }\end{array}$ \\
\hline $\begin{array}{l}\text { Edifício } \\
\text { Ijuí }\end{array}$ & & $\begin{array}{l}\text { Jaboatão } \\
\text { dos } \\
\text { Guararapes }\end{array}$ & $\begin{array}{l}\text { Colapso dos embasamentos } \\
\text { provocados pelo descalçamento } \\
\text { das sapatas corridas em } \\
\text { decorrência da passagem das } \\
\text { águas servidas e pluviais/2011 }\end{array}$ \\
\hline $\begin{array}{l}\text { Edifício } \\
\text { Sevilha }\end{array}$ & & $\begin{array}{l}\text { Jaboatão } \\
\text { dos } \\
\text { Guararapes }\end{array}$ & $\begin{array}{l}\text { Houve a ruptura localizada dos } \\
\text { embasamentos na região da } \\
\text { fachada correspondente à } \\
\text { entrada do prédio. Com isso } \\
\text { ocorreu a ruptura generalizada, } \\
\text { como se o prédio tivesse } \\
\text { "afundado"/2007 }\end{array}$ \\
\hline
\end{tabular}


Figura 3 - Vista lateral do Residencial Eldorado após o colapso

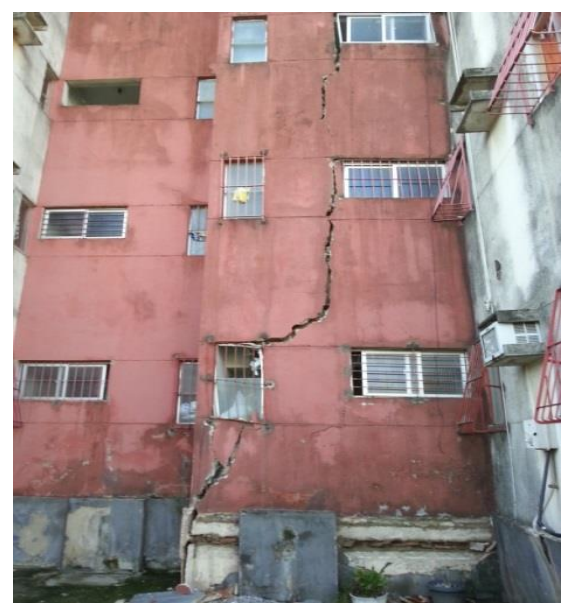

Figura 4 - Detalhe do esmagamento da alvenaria entre a viga de fundação e a laje de piso do térreo

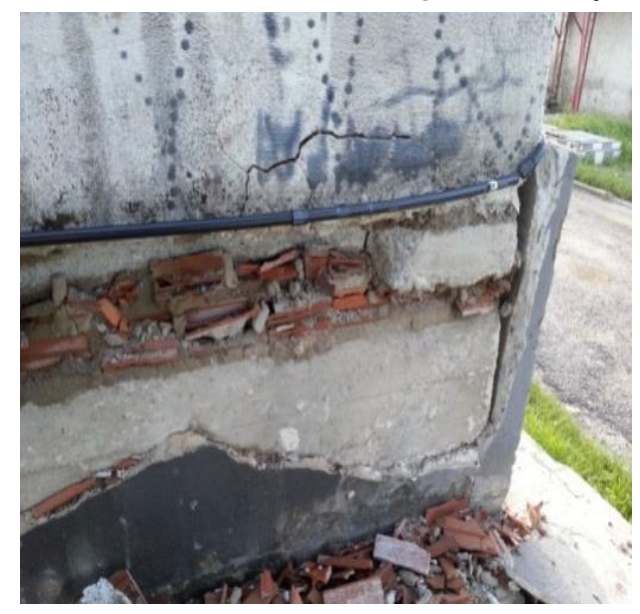

Tabela 1 - Características médias dos blocos ensaiados

(a) Blocos cerâmicos - NBR 15270-1 (ABNT, 2005)

\begin{tabular}{l|r}
\hline Comprimento $(\mathrm{mm})$ & 190 \\
\hline Largura $(\mathrm{mm})$ & 90 \\
\hline Altura $(\mathrm{mm})$ & 190 \\
\hline Espessura dos septos horizontais e verticais $(\mathrm{mm})$ & 7,0 \\
\hline Resistência à compressão $(\mathbf{M P a})$ & $\mathbf{2 , 1 5}$ \\
\hline
\end{tabular}

(b) Blocos de concreto - NBR 6136 (ABNT, 2014)

\begin{tabular}{l|r}
\hline Comprimento (mm) & 390 \\
\hline Largura (mm) & 90 \\
\hline Altura (mm) & 190 \\
\hline Espessura dos septos longitudinais (mm) & 21,5 \\
\hline Espessura dos septos transversais internos (mm) & 22,5 \\
\hline Espessura dos septos transversais externos (mm) & 25,0 \\
\hline Resistência à compressão (MPa) & $\mathbf{2 , 3 0}$ \\
\hline
\end{tabular}

\section{Areias e argamassas de assentamento e de revestimento}

A areia utilizada na confecção das argamassas de assentamento e revestimentos dos modelos ensaiados é a usualmente encontrada na RMR e todo o lote utilizado no desenvolvimento da pesquisa foi adquirido do mesmo fornecedor. A Tabela 2 resume os resultados da caracterização da areia.

180 Oliveira, R. A.; Silva, F. A. N.; Pires Sobrinho, C. W. de A.; Azevedo, A. A. C. de 
As argamassas utilizadas, tanto no assentamento dos blocos (de concreto ou cerâmicos) quanto no revestimento, foram definidas a partir de misturas de cimento, cal e areia nas proporções 1:2:9, 1:1:6, e 1:0,5:4,5, em volume.

A Tabela 3 apresenta os valores da resistência à compressão das argamassas, obtidos por meio de ensaios de 15 corpos de prova em conformidade com as normas brasileiras NBR 7215 (ABNT, 1997) e NBR 7222 (ABNT, 2011c). A quantidade de cimento utilizada nas argamassas foi de 300 $\mathrm{kg} / \mathrm{m}^{3}$ para o traço $1: 0,5: 4,5$, de $220 \mathrm{~kg} / \mathrm{m}^{3}$ para o traço $1: 1: 6$ e de $150 \mathrm{~kg} / \mathrm{m}^{3}$ para o traço $1: 2: 9$.

No caso dos blocos de concreto, os cordões de argamassa de assentamento foram aplicados tanto nos septos longitudinais quanto nos septos transversais, situação que é usualmente referida como assentamento total.

\section{Telas de aço e conectores}

Foram utilizados dois tipos de telas para armação da capa de revestimento dos prismas ensaiados: uma com tela de aço galvanizado e outra com tela eletrossoldada de aço. A tela galvanizada é formada de fios com diâmetro de $2,7 \mathrm{~mm}$ e espaçamento de $5 \mathrm{~cm}$ na direção horizontal e 10 $\mathrm{cm}$ na vertical, perfazendo uma área de aço de 1,06 $\mathrm{cm} 2 / \mathrm{m}$ e $0,53 \mathrm{~cm}^{2} / \mathrm{m}$, respectivamente. A tela de aço eletrossoldada possuía fios com diâmetro de $4,2 \mathrm{~mm}$ e espaçamento de $10 \mathrm{~cm}$ nas direções horizontal e vertical, o que perfaz uma seção de aço de $1,38 \mathrm{~cm} 2 / \mathrm{m}$ nas duas direções. As telas e os conectores utilizados foram de aço CA-60, esses últimos de diâmetro igual a $5 \mathrm{~mm}$.

\section{Prismas}

Foram ensaiados aproximadamente 500 prismas compostos de três blocos (de concreto ou cerâmicos) justapostos na vertical. Desse total, cerca de 300 foram prismas de blocos cerâmicos e 200 de blocos de concreto. Os prismas ensaiados são compostos de três blocos de concreto ou cerâmicos justapostos ao longo da altura. Todos os prismas foram capeados no topo e na base com pasta de cimento numa espessura de $5 \mathrm{~mm}$ com a finalidade de se obter uma superfície uniforme e nivelada. Os prismas foram confeccionados procurando-se reproduzir as condições encontradas na prática executiva das construções em alvenaria resistente. A tipologia dos prismas ensaiados acompanhados do respectivo acrônimo é apresentada a seguir:

(a) prismas de blocos de concreto e blocos cerâmicos sem revestimento (PSR);

(b) prismas de blocos de concreto e blocos cerâmicos com 3,0 cm de revestimento de argamassa (PR30MM);

(c) prismas de blocos de concreto e blocos cerâmicos com $3,0 \mathrm{~cm}$ de revestimento com adição de tela (pop (PCRTP) e galvanizada (PCRTG));

(d) prismas de blocos de concreto e blocos cerâmicos com $3,0 \mathrm{~cm}$ de revestimento com tela e conectores (PCRTG - C e PCRTP - C); eprismas de blocos de concreto e blocos cerâmicos reforçados com argamassa armada com $3,0 \mathrm{~cm}$ com tela e conectores (PRAATG-C e PRAATP-C).

Todos os prismas foram inicialmente revestidos com uma camada de $5 \mathrm{~mm}$ de chapisco no traço 1:3 e, depois de transcorridas 24 horas, receberam uma camada adicional de revestimento de $2,5 \mathrm{~cm}$, num traço 1:1:6 (cimento, cal e areia) em volume. Os prismas foram submetidos a processo de cura em condições naturais por um período de no mínimo 28 dias.

Tabela 2 - Características da areia natural utilizada

\begin{tabular}{l|l}
\hline Dimensão máxima característica - NBR 7211 (ABNT, 2009) & $4,80 \mathrm{~mm}$ \\
\hline Módulo de finura - NBR NM 248 (ABNT, 2003) & 3,20 \\
\hline Massa unitária - NBR NM 45 (ABNT, 2006b) & $1,42 \mathrm{~g} / \mathrm{cm}^{3}$ \\
\hline Massa específica - NBR 9776 (ABNT, 1998) & $2,60 \mathrm{~g} / \mathrm{cm}^{3}$ \\
\hline Inchamento - NBR 6467 (ABNT, 2006a) & 1,25 \\
\hline Umidade crítica - NBR 6467 (ABNT, 2006a) & $3,00 \%$ \\
\hline Teor de material pulverulento - NBR 7219 (ABNT, 1982) & $1,26 \%$ \\
\hline
\end{tabular}

Tabela 3 - Resistência à compressão das argamassas utilizadas

\begin{tabular}{l|c|c|c}
\hline \multirow{2}{*}{ Item } & \multicolumn{3}{|c}{ Valores médios } \\
\cline { 2 - 4 } & $\mathbf{1 : 2 : 9}$ & $\mathbf{1 : 1 : 6}$ & $\mathbf{1 : 0 , 5 : 4 , 5}$ \\
\hline Resistência à compressão $-\mathrm{MPa}$ & 4,00 & 5,80 & 6,23 \\
\hline
\end{tabular}


A execução do revestimento dos prismas com adição de tela e camada de $3,0 \mathrm{~cm}$ foi realizada em quatro etapas, conforme descrito a seguir:

(a) aplicação do chapisco;

(b) aplicação de uma camada de argamassa (1,0 cm de espessura);

(c) aplicação e fixação da tela por meio dos conectores de aço; e

(d) aplicação de uma segunda camada de argamassa de revestimento de $1,5 \mathrm{~cm}$ de espessura deixando a tela totalmente imersa na argamassa.

Os prismas que receberam o reforço de argamassa armada adicional sobre o revestimento sem tela já existente foram confeccionados inicialmente obedecendo ao mesmo roteiro estabelecido para os prismas com 3,0 $\mathrm{cm}$ de revestimento e sem tela, que foram revestidos em uma única etapa por meio de gabaritos de madeira.

Transcorrida essa etapa e após um período de cura de 28 dias, foram realizados furos transversais nos prismas por onde foram introduzidos os conectores de aço para fixação das telas sobre a superfície do revestimento. Completada essa operação, a segunda camada de argamassa de revestimento foi aplicada sobre a tela, deixando-a completamente envolvida, e o produto final se constituiu numa camada com espessura de $6,0 \mathrm{~cm}$. Todos os prismas foram capeados com pasta de cimento no topo e na base. $\mathrm{O}$ transporte dos protótipos para a máquina de ensaios exigiu cuidados especiais a fim de se evitar danos às amostras. A velocidade de carregamento utilizada nos ensaios foi de 0,05 $\mathrm{MPa} / \mathrm{s}$.

\section{Miniparedes}

A miniparede é um elemento mais representativo de uma parede de alvenaria por considerar a influência da argamassa de rejuntamento vertical e a amarração entre os blocos. Para analisar a influência do traço da argamassa, da espessura de revestimento e do reforço com tela intertravada com conectores de aço, foram confeccionadas e ensaiadas 154 miniparedes nas dimensões $0,09 \mathrm{~m}$ x 0,60 m x 1,20 m, utilizando blocos cerâmicos de oito furos com dimensões de $9 \mathrm{~cm}$ x $19 \mathrm{~cm}$ x 19 $\mathrm{cm}$, assentados com argamassa mista de cimento, cal e areia, no traço volumétrico de 1:1:6. A Figura 5 exibe os tipos de miniparedes ensaiadas (ANDRADE, 2007).

\section{Figura 5 - Esquemas típicos das miniparedes ensaiadas}

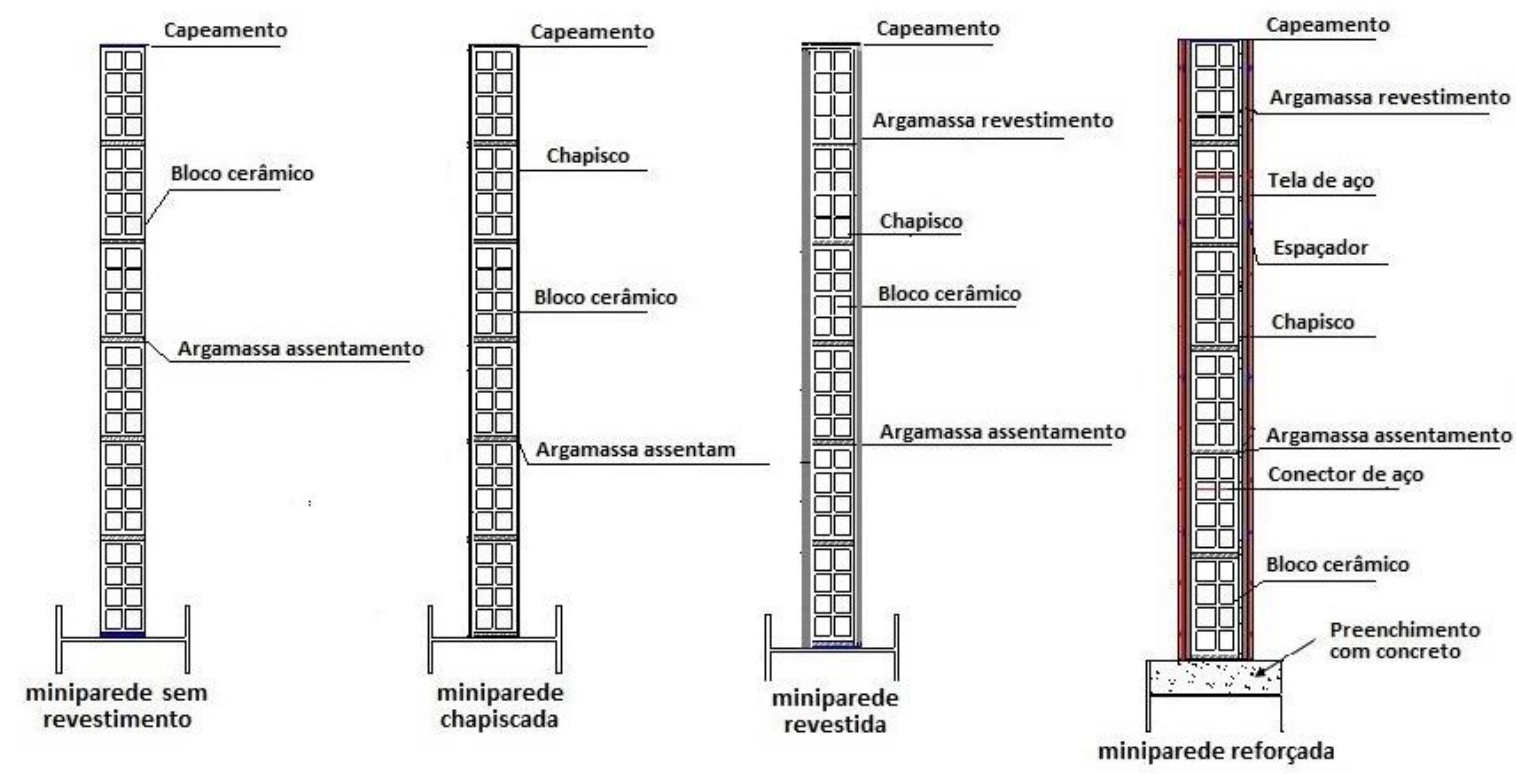


A Tabela 4 apresenta as características das miniparedes ensaiadas. De cada tipo, foram confeccionados 15 exemplares.

As miniparedes foram confeccionadas em etapas de três fiadas/dia utilizando argamassa de assentamento com espessura de $1,0 \mathrm{~cm}$. Foram construídas sobre perfis metálicos $\mathrm{H}$ de 8" preenchidos com concreto, para possibilitar o revestimento das miniparedes após a colocação da tela.
As telas utilizadas foram as mesmas dos ensaios de prismas, tanto no que diz respeito ao diâmetro quanto aos espaçamentos horizontais e verticais. A Figura 6 mostra as etapas de confecção das miniparedes (ANDRADE, 2007).

A Figura 7 apresenta o processo construtivo utilizado para a incorporação do reforço com tela de aço e recobrimento com argamassa.

Tabela 4 - Características das miniparedes

\begin{tabular}{c|c|c|c|l}
\hline Referência & Chapisco & $\begin{array}{c}\text { Argamassa de } \\
\text { revestimento }\end{array}$ & $\begin{array}{c}\text { Revestimento em } \\
\text { cada face (cm) }\end{array}$ & \multicolumn{1}{|c}{ Observações } \\
\hline 1 & - & - & - & Aparente \\
2 & $1: 3$ & - & - & Chapiscada \\
3 & $1: 3$ & $1: 2: 9$ & 1,5 & Sem tela \\
4 & $1: 3$ & $1: 2: 9$ & 3,0 & Sem tela \\
5 & $1: 3$ & $1: 1: 6$ & 3,0 & Sem tela \\
6 & $1: 3$ & $1: 0,5: 4,5$ & 3,0 & Sem tela \\
7 & $1: 3$ & $1: 1: 6$ & 3,0 & Sem tela, com aditivo \\
8 & $1: 3$ & $1: 2: 9$ & 3,0 & Com tela \\
9 & $1: 3$ & $1: 2: 9$ & 1,5 & Com tela \\
10 & $1: 3$ & $1: 1: 6$ & 3,0 & Com tela \\
\hline
\end{tabular}

Figura 6 - Etapas de execução das miniparedes

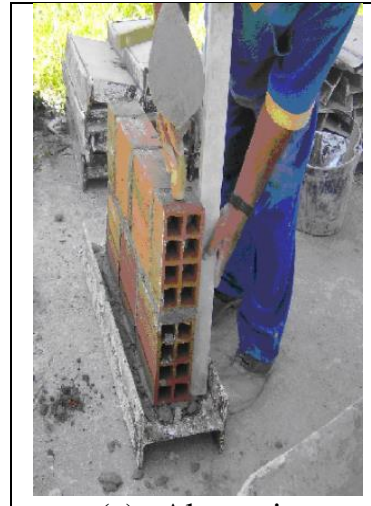

(a) Alvenaria

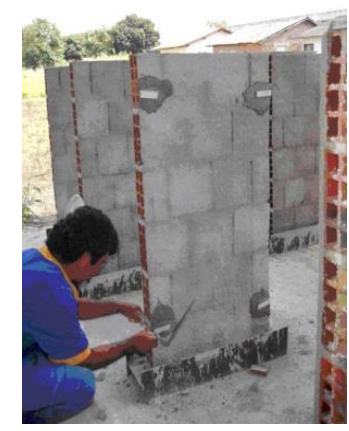

(b) Chapisco e mestras

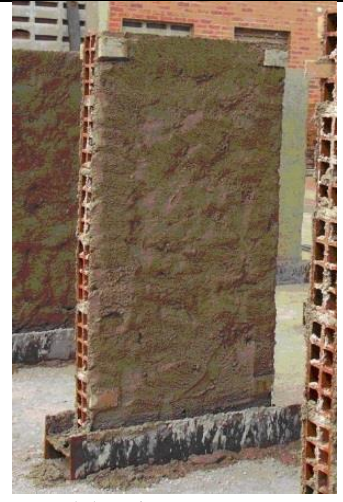

(c) Argamassa

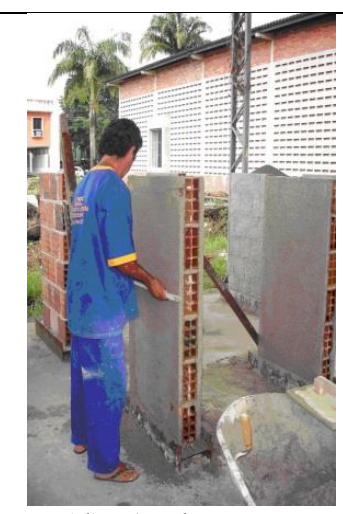

(d) Acabamento

Figura 7 - Etapas de instalação dos conectores nas miniparedes

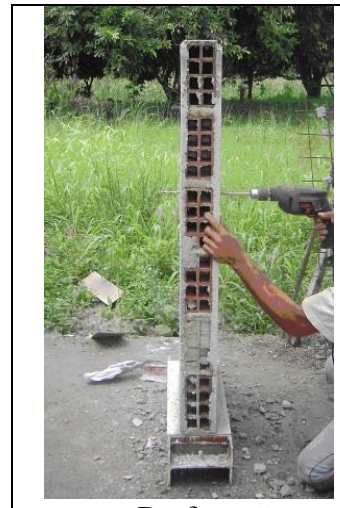

(a) Perfuração

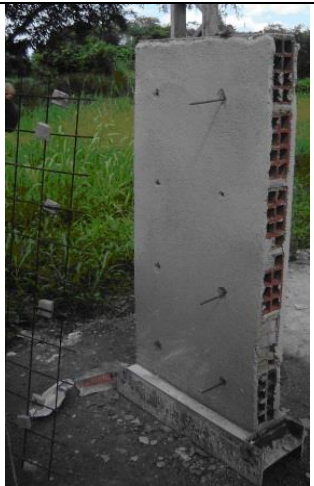

(b) Instalação das telas

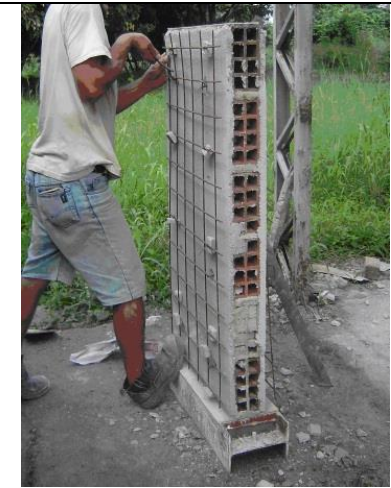

(c) Ancoragem dos conectores

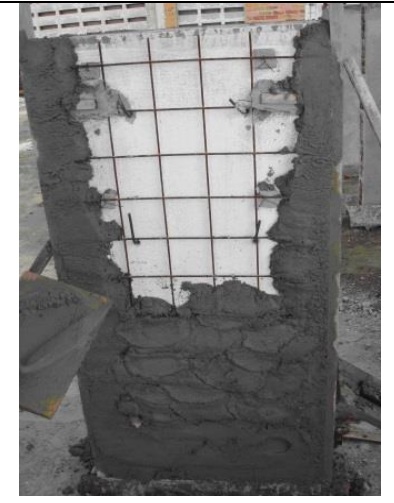

(d) Argamassa 
A execução do capeamento e preparação das miniparedes exigiu o desenvolvimento de equipamentos e dispositivos de transporte $\mathrm{e}$ manuseio especiais. $\mathrm{O}$ dispositivo para transporte das paredes se constitui num pórtico sobre quatro rodas, dotado de talha e mecanismo de sustentação, com rolamento na sua parte central, que permite o movimento da parede no seu próprio plano sem lhe gerar nenhum dano. A movimentação da parede possibilitou, adicionalmente, a realização do capeamento nas faces superior e inferior do modelo a ser ensaiado. A Figura 8 exemplifica as etapas de acabamento do capeamento superior (a) e o transporte dos modelos (b) e (c).
Os ensaios foram realizados em um pórtico de reação com controle de deslocamento por meio de mecanismo servomotor. Estruturado na forma de quadro autorreativo, o pórtico possui três macacos hidráulicos com capacidade de carga de $500 \mathrm{kN} \mathrm{e}$ curso de $200 \mathrm{~mm}$. A Figura 9 apresenta a disposição esquemática do pórtico de reação e detalhes dos equipamentos e dispositivos utilizados nos ensaios das miniparedes. A velocidade de carregamento utilizada nos ensaios foi de $0,05 \mathrm{MPa} / \mathrm{s}$. A localização dos sensores de deslocamentos (LVDTs) utilizados na instrumentação dos modelos ensaiados acha-se igualmente indicada nesta figura.

Figura 8- Etapas de capeamento e manuseio das miniparedes

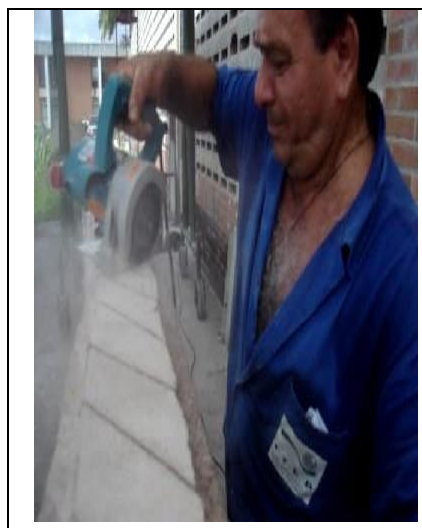

(a) Capeamento

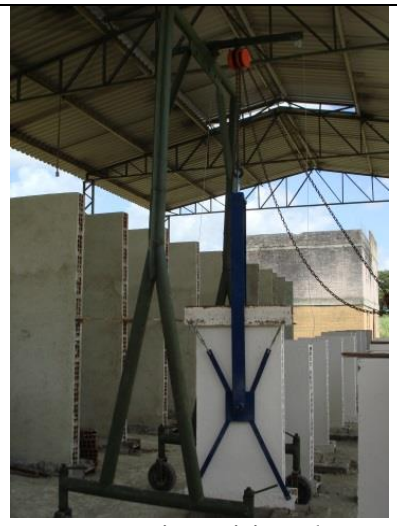

(b) Dispositivo de transporte

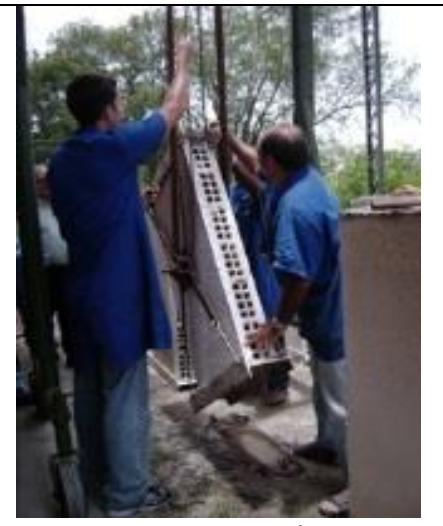

(c) Manuseio

Figura 9 - Representação esquemática do pórtico de reação e dispositivos dos ensaios das miniparedes

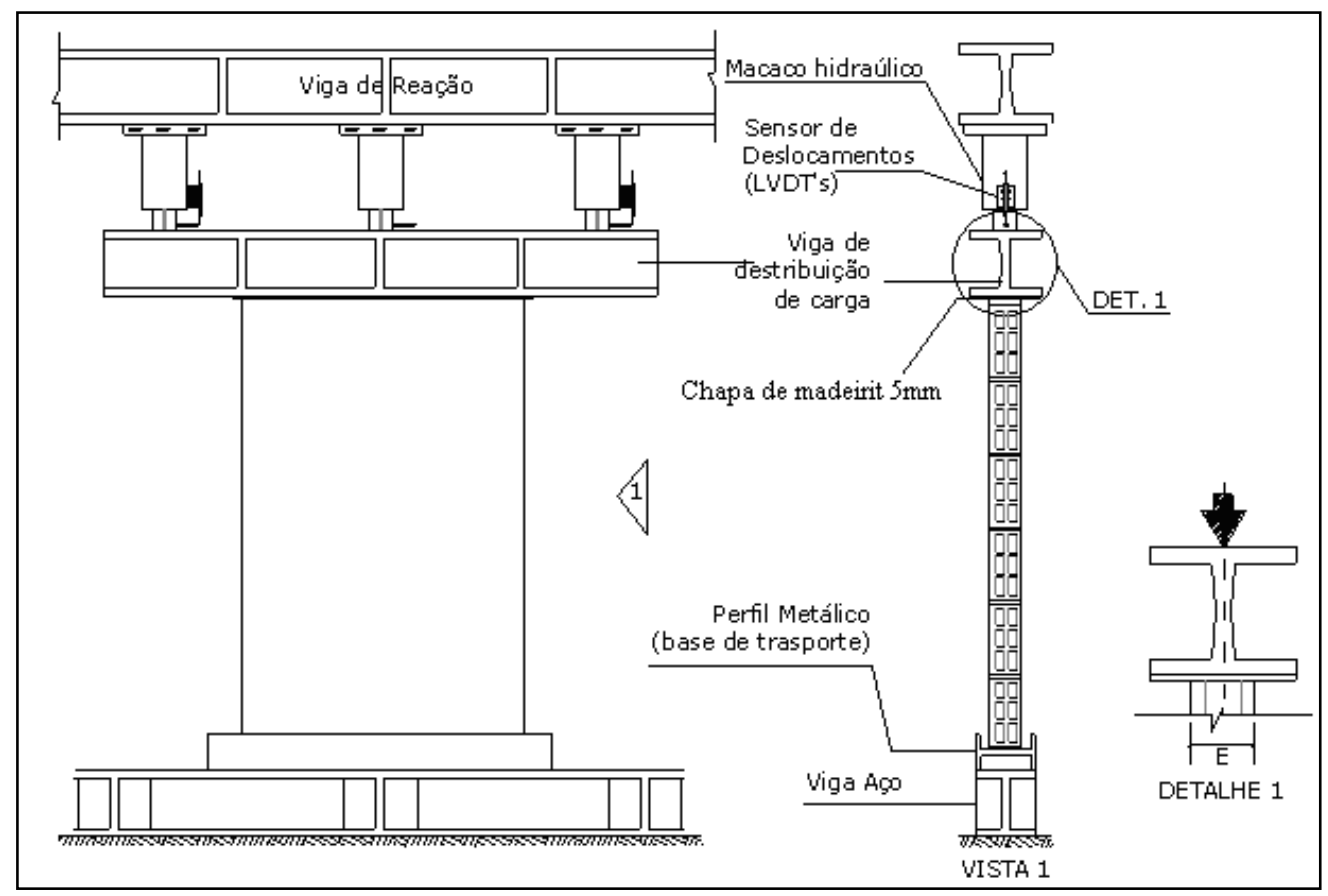

184 Oliveira, R. A.; Silva, F. A. N.; Pires Sobrinho, C. W. de A.; Azevedo, A. A. C. de 


\section{Análise dos resultados}

A seguir são apresentados e discutidos os resultados dos diversos ensaios realizados.

\section{Prismas de blocos cerâmicos}

As Figuras 10, 11, 12 e 13 ilustram os perfis de ruptura observados nos prismas de blocos cerâmicos ensaiados. Quando presente, a numeração dos prismas constante nas figuras representa corpos de prova distintos de uma série ensaiada.

Como podem ser observadas, as rupturas são frágeis e explosivas, e se caracterizam por uma perda imediata da capacidade resistente do sistema logo após atingir a carga máxima. Para os prismas com revestimento foi observado que o processo de fissuração se inicia nos septos horizontais dos blocos e, a partir desse momento, a carga é primordialmente resistida pelas duas capas de revestimento. Deve-se registrar, no entanto, que várias formas de ruptura foram constatadas, não se podendo estabelecer uma que represente o universo dos prismas ensaiados. Vários fatores podem influenciar esse processo, tais como: a qualidade da mão de obra, a espessura e uniformidade da argamassa de assentamento e de revestimento, entre outros. Não obstante, podem-se destacar as seguintes formas de rupturas como mais frequentes (MOTA, 2006):

(a) ruptura da capa de revestimento causada por deslocamentos laterais excessivos da argamassa de assentamento (Figura 11, terceira foto);

(b) ruptura por descolamento das capas de revestimento; e

(c) ruptura por flambagem da capa de revestimento sem conectores (Figura 12, terceira foto).

A Tabela 5 sumariza as cargas de ruptura dos prismas.

\section{Figura 10 - Prismas de blocos cerâmicos sem revestimento: evolução da ruptura}
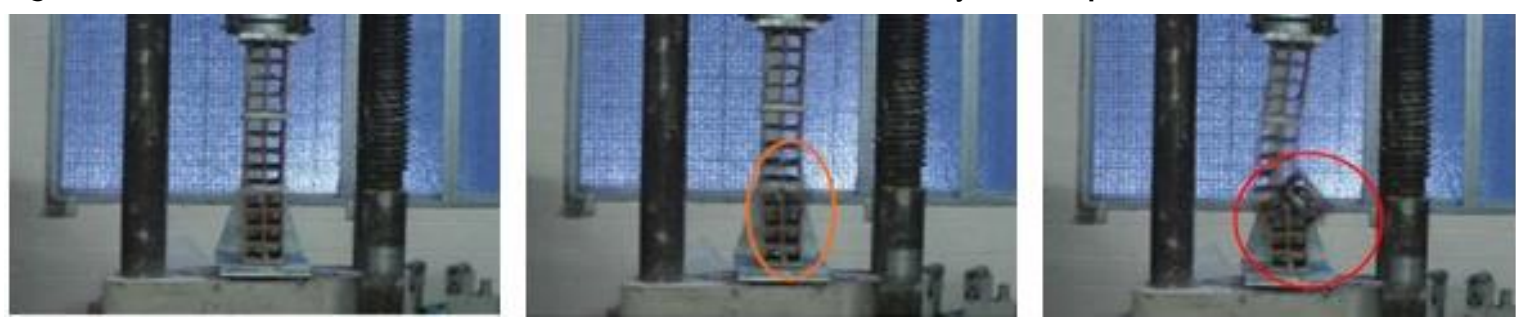

Figura 11 - Prismas de blocos cerâmicos com revestimento: evolução da ruptura
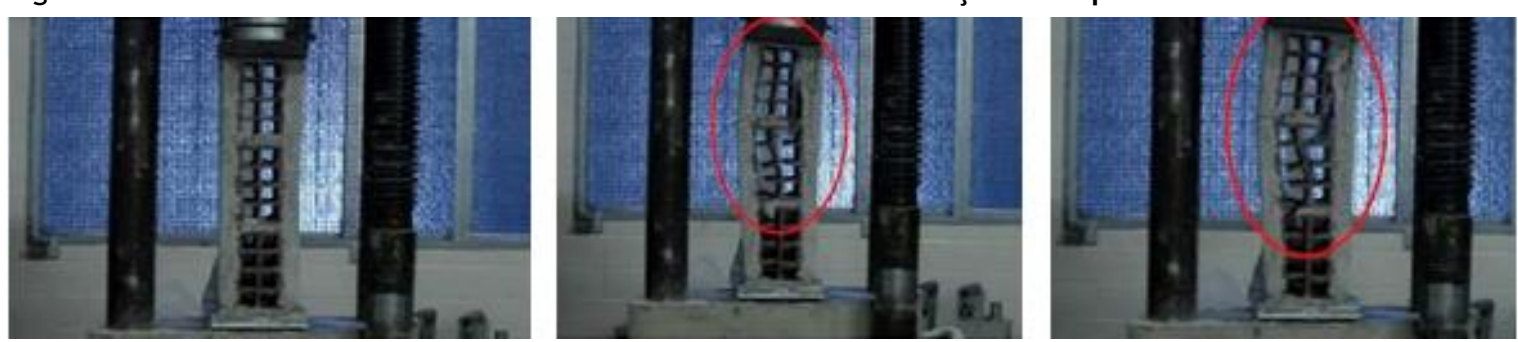

Figura 12 - Prismas de blocos cerâmicos com revestimento e tela: prismas distintos no momento da ruptura
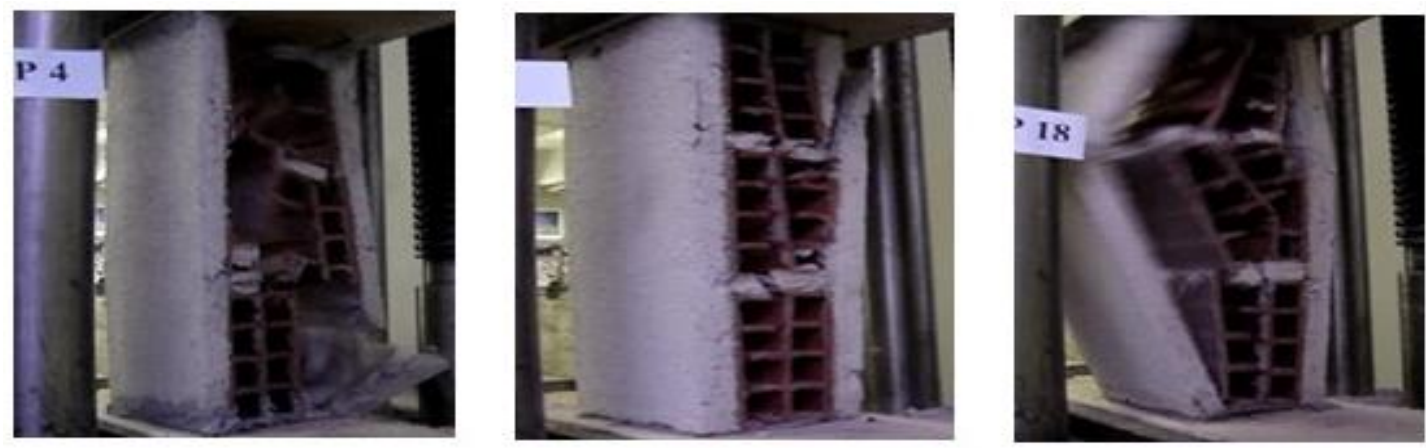
Figura 13 - Prismas de blocos cerâmicos com reforço de argamassa armada com conectores: evolução da ruptura
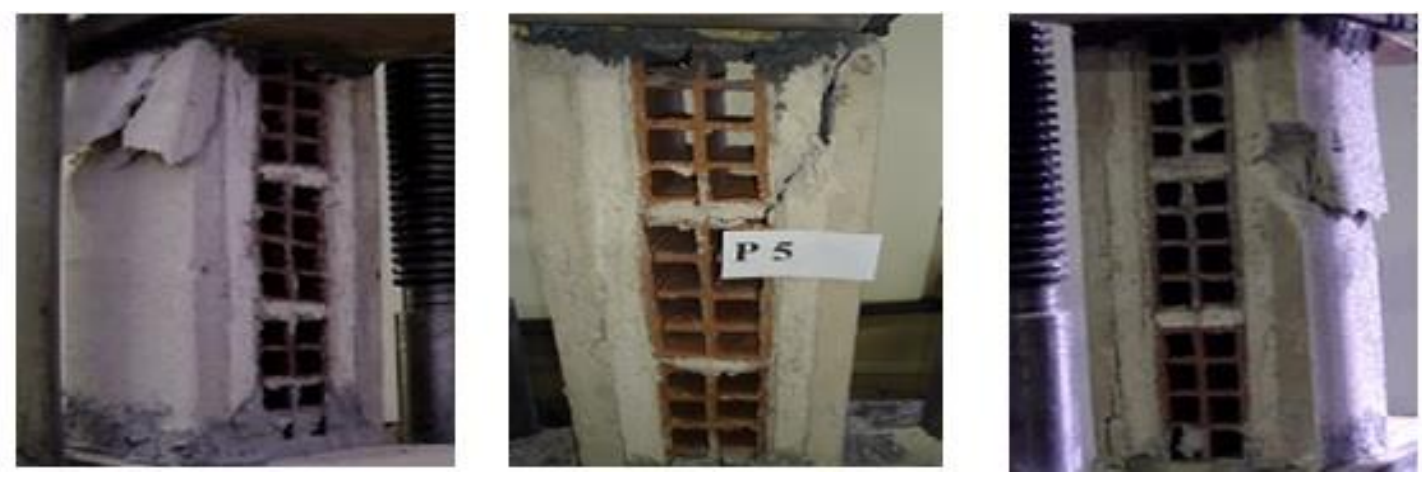

Tabela 5 - Carga de ruptura dos prismas de blocos cerâmicos - Blocos com $\mathrm{f}_{\mathrm{bk}}=2,15 \mathrm{MPa}$

\begin{tabular}{|c|c|c|c|c|}
\hline \multirow[b]{2}{*}{ Protótipo } & \multirow{2}{*}{$\begin{array}{c}\text { Carga } \\
\text { média } \\
\text { de } \\
\text { ruptura } \\
(\mathbf{k N})\end{array}$} & \multicolumn{2}{|c|}{$\begin{array}{c}\text { Medidas de } \\
\text { dispersão }\end{array}$} & \multirow{2}{*}{$\begin{array}{c}\text { Carga de } \\
\text { ruptura } \\
\text { característica } \\
(\mathbf{k N})\end{array}$} \\
\hline & & $\begin{array}{c}\text { Desvio } \\
\text { padrão } \\
(\mathrm{kN})\end{array}$ & $\begin{array}{c}\text { COV } \\
(\%)\end{array}$ & \\
\hline Prisma sem revestimento (PSR) & 32,46 & 6,52 & 20,11 & 21,70 \\
\hline Prismas apenas chapiscados ( $5 \mathrm{~mm})$ & 43,35 & 7,35 & 21,25 & 31,22 \\
\hline Prismas revestidos com $30 \mathrm{~mm}$ (PR30MM) & 74,93 & 13,90 & 18,55 & 52,00 \\
\hline Prismas revestidos com tela eletrossoldada (PRCTP) & 98,07 & 19,46 & 19,84 & 65,96 \\
\hline Prismas revestidos com tela galvanizada (PRCTG) & 92,86 & 21,59 & 23,25 & 57,23 \\
\hline Prismas reforçados com tela eletrossoldada (PRAATP-C) & 205,44 & 16,06 & 7,82 & 178,93 \\
\hline Prismas reforçados com tela galvanizada (PRAATG-C) & 150,18 & 25,33 & 16,86 & 108,39 \\
\hline
\end{tabular}

Conforme se observa, o incremento na capacidade de carga decorrente do revestimento do prisma é significativo. Quando se compara a carga média de ruptura do prisma sem revestimento com aquela do prisma revestido unicamente com chapisco, observa-se um incremento de aproximadamente $33 \%$. Ao se comparar os valores obtidos para o prisma revestido com o do prisma sem nenhum revestimento, verifica-se um acréscimo na carga média de ruptura de aproximadamente $130 \%$, aspecto que consubstancia um significativo incremento gerado pelo revestimento de argamassa. O incremento obtido com a colocação da malha de aço no interior da argamassa de revestimento foi de $31 \%$ e $24 \%$, para tela eletrossoldada e tela galvanizada, respectivamente. A ruptura observada nos prismas ensaiados foi sempre brusca, tanto para prismas revestidos quanto para prismas sem revestimento. A ruptura se deu por falência dos septos horizontais dos blocos por tração seguida do colapso dos septos correspondentes às juntas de argamassa, ocasionando o desequilíbrio do conjunto. Os prismas revestidos, reforçados com malha de aço e conectores também apresentaram ruptura brusca, no entanto com cargas compressivas bem superiores aos demais. Isso se deve à presença dos conectores e sua ação de impedimento dos deslocamentos horizontais dos septos.

Os modelos que apresentaram maior carga média de ruptura, com menor coeficiente de variação, foram aqueles reforçados com tela eletrossoldada e conectores de aço.

Análises com variação de espessuras e traços da argamassa foram adicionalmente realizados e os detalhes reforçam as observações acima elencadas. Maiores detalhes podem ser encontrados no livro intitulado Alvenaria resistente: uma investigação experimental e numérica sobre seu comportamento compressivo (OLIVEIRA; SILVA; SOBRINHO, 2011).

\section{Prismas de blocos de concreto}

As cargas de ruptura dos prismas de blocos de concreto ensaiados acham-se detalhadas na Tabela 6.

Conforme se observa, o incremento na capacidade de carga decorrente do revestimento do prisma foi significativo. Com efeito, no caso do revestimento sem tela, o aumento na carga média de ruptura, quando comparado com o prisma sem

${ }^{1}$ A carga característica é a carga que tem uma probabilidade de falha de $5 \%$, considerando uma distribuição normal. 
revestimento, foi de aproximadamente $72 \%$, ao passo que para o caso do revestimento com adição de tela o incremento atingiu $159 \%$ e $117 \%$ para a tela eletrossoldada e tela de aço galvanizado, respectivamente. Foi também possível observar que a existência da tela no interior do revestimento concorreu para um acréscimo na capacidade de carga do prisma com revestimento. No caso de tela eletrossoldada, o acréscimo médio observado foi de aproximadamente $51 \%$, e para o caso de tela de aço galvanizado esse incremento foi de $27 \%$. Esse comportamento indica uma importante participação da tela que pode ser explorada para eventuais soluções de recuperação. Da Figura 10 até a Figura 18 acham-se representados os modos de rupturas observados para os prismas sem revestimento e com revestimento (ARAÚJO NETO, 2006; AZEVÊDO, 2010). Quando presente, a numeração dos prismas constante nas figuras representa corpos de prova distintos de uma série de corpos de prova ensaiados.

Tabela 6 - Cargas de ruptura dos prismas de blocos de concreto - Blocos com $\mathrm{f}_{\mathrm{bk}}=2,30 \mathrm{MPa}$

\begin{tabular}{|c|c|c|c|c|}
\hline \multirow[b]{2}{*}{ Corpos de prova } & \multirow{2}{*}{$\begin{array}{l}\text { Carga } \\
\text { média de } \\
\text { ruptura } \\
(\mathbf{k N})\end{array}$} & \multicolumn{2}{|c|}{$\begin{array}{l}\text { Medidas de } \\
\text { dispersão }\end{array}$} & \multirow{2}{*}{$\begin{array}{c}\text { Carga de } \\
\text { ruptura } \\
\text { característica } \\
(\mathbf{k N})\end{array}$} \\
\hline & & $\begin{array}{c}\text { Desvio } \\
\text { padrão } \\
(\mathbf{k N})\end{array}$ & $\begin{array}{c}\mathrm{COV} \\
(\%)\end{array}$ & \\
\hline Prisma sem revestimento (PSR) & 86,22 & 11,47 & 13,30 & 67,30 \\
\hline Prismas revestidos com $3 \mathrm{~cm}$ (PCR) & 148,23 & 19,89 & 13,42 & 115,41 \\
\hline $\begin{array}{l}\text { Prismas revestidos com tela eletrossoldada } \\
\text { (PCRTP) }\end{array}$ & 223,43 & 17,07 & 7,64 & 195,26 \\
\hline $\begin{array}{l}\text { Prismas revestidos com tela galvanizada } \\
\text { (PCRTG) }\end{array}$ & 187,30 & 14,11 & 7,53 & 164,02 \\
\hline $\begin{array}{l}\text { Prismas reforçados com tela eletrossoldada e } \\
\text { conectores (PCRTP-C) }\end{array}$ & 251,70 & 36,43 & 14,47 & 191,59 \\
\hline $\begin{array}{l}\text { Prismas reforçados com tela galvanizada e } \\
\text { conectores (PCRTG-C) }\end{array}$ & 233,36 & 32,61 & 13,97 & 179,56 \\
\hline $\begin{array}{l}\text { Prismas reforçados com tela eletrossoldada } \\
\text { (PRAATP-C) }\end{array}$ & 371,36 & 38,37 & 10,33 & 308,06 \\
\hline $\begin{array}{l}\text { Prismas reforçados com tela galvanizada } \\
\text { (PRAATG-C) }\end{array}$ & 392,42 & 34,80 & 8,87 & 335,03 \\
\hline
\end{tabular}

Figura 14 - Ruptura dos prismas de blocos de concreto sem revestimento: prismas distintos
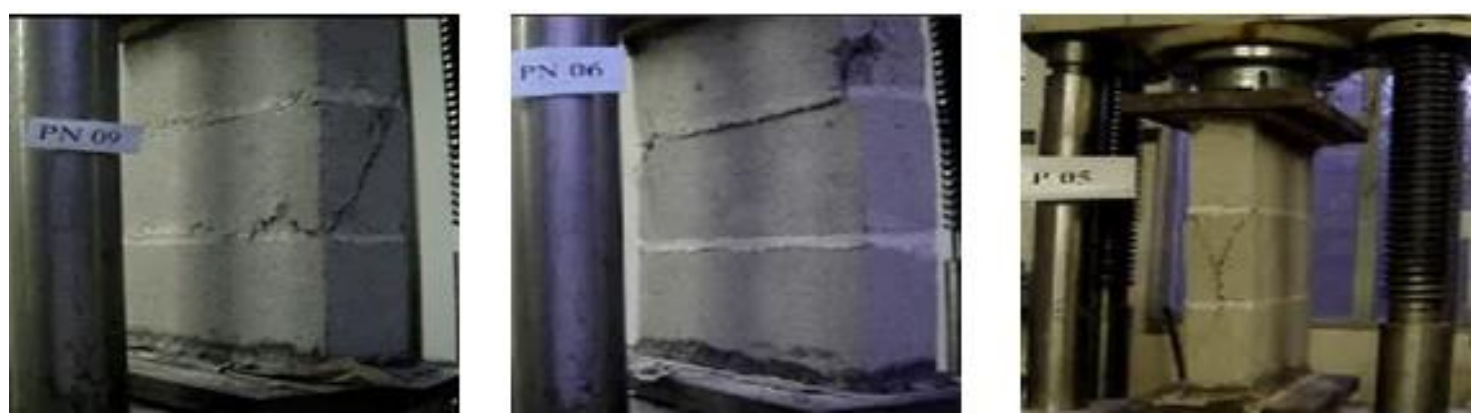

Figura 15 - Ruptura dos prismas de blocos de concreto com revestimento, sem tela: prismas distintos
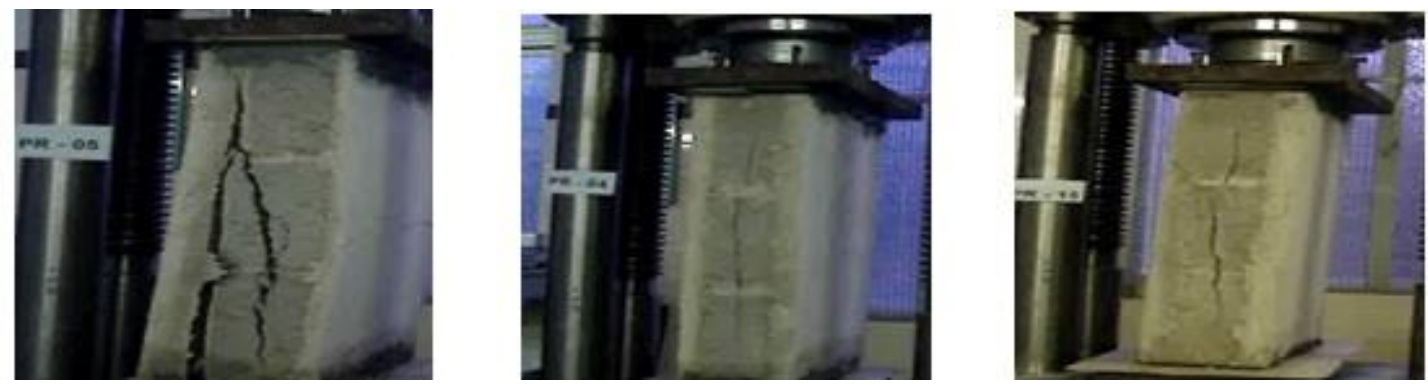
Figura 16 - Ruptura dos prismas com revestimento, com tela: prismas distintos
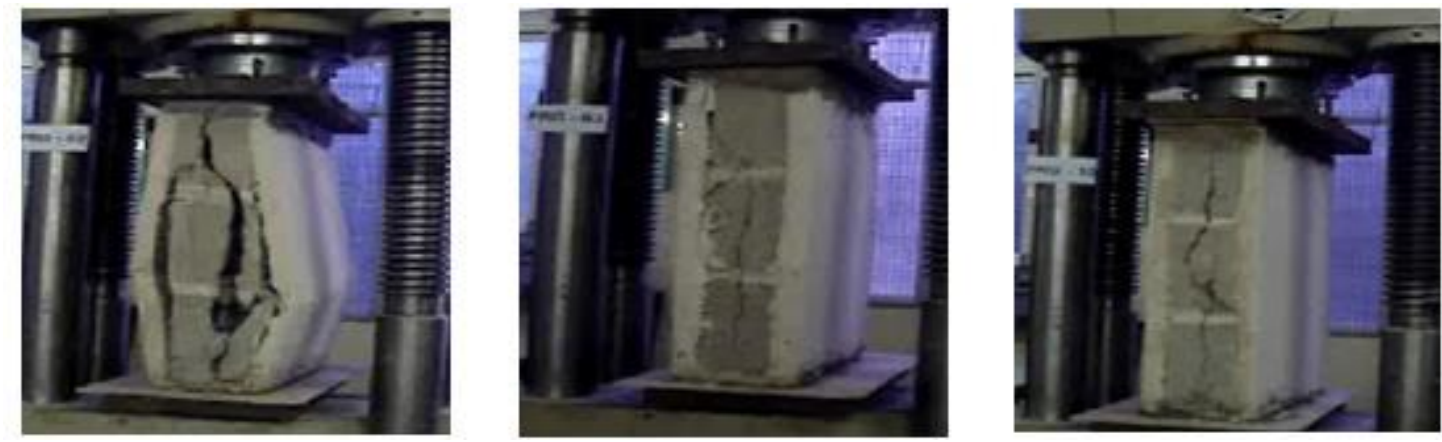

Figura 17 - Ruptura dos prismas com revestimento, com tela e conectores: prismas distintos
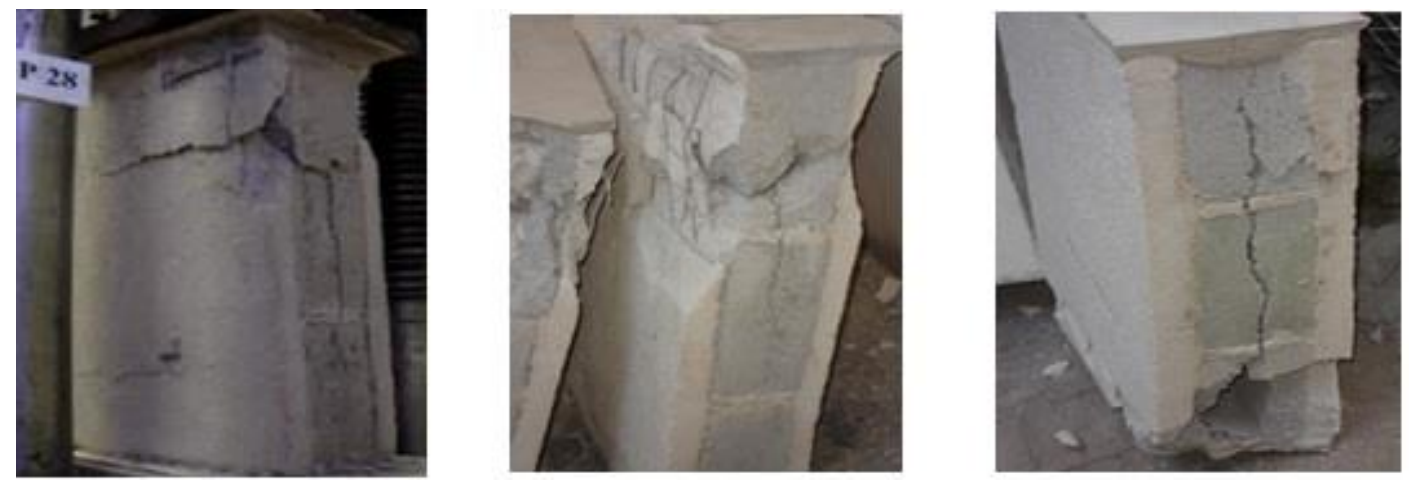

Figura 18 - Ruptura dos prismas com reforço de argamassa com tela de aço: prismas distintos
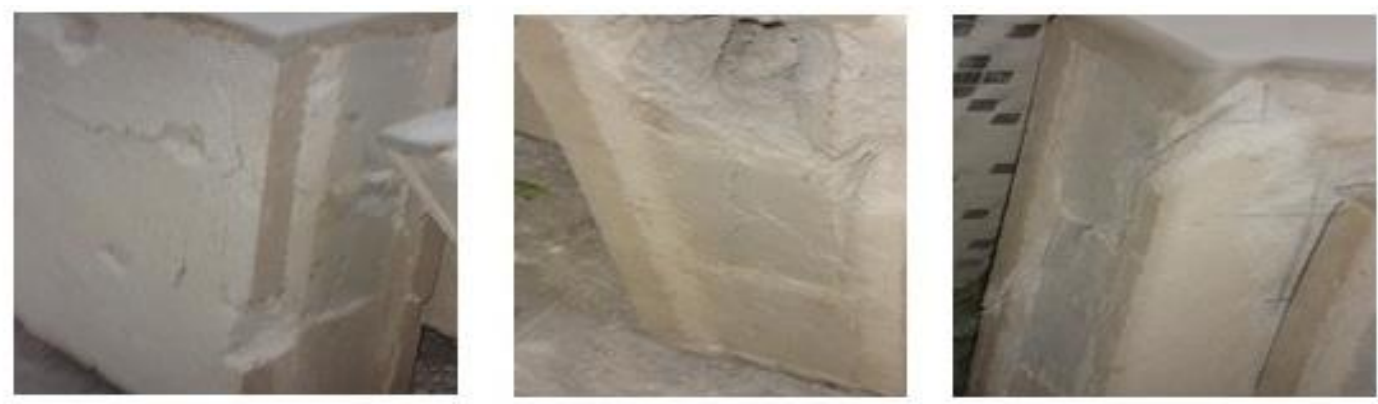

No caso dos prismas de blocos de concreto sem revestimentos as fissuras observadas se localizavam nas faces dos blocos e na superfície de assentamento. As primeiras apresentaram uma característica marcadamente aleatória ao passo que as segundas apresentaram um padrão com maior regularidade.

A ruptura observada foi menos brusca do que aquela registrada nos prismas sem revestimento feitos com blocos cerâmicos e em alguns dos prismas foram observados desplacamentos das paredes dos blocos, conforme se vê na Figura 14.

Para os prismas revestidos, sem adição de tela de aço no interior da argamassa, o modo de ruptura mais frequente acha-se indicado na Figura 15. Esse tipo de ruptura foi caracterizado por um processo de fissuração localizado nas faces anterior e posterior dos blocos, o que sugere uma ruptura gerada por tensões transversais de tração.

Para os prismas com revestimento com adição de tela de aço no interior da argamassa, o modo de ruptura mais frequente acha-se indicado na Figura 16. Foi semelhante àquele observado para os prismas com revestimento e sem tela. Merece destaque, entretanto, a melhoria de desempenho gerada pela existência da tela de aço e o fato de que nos ensaios realizados foi nitidamente observada uma diferença de comportamento, caracterizada por uma ligeira alteração no processo de ruptura que, devido à existência da tela, mostrou-se menos brusca do que aquela observada nos prismas revestidos apenas com argamassa. 
Outro aspecto que merece registro foi a maior regularidade no valor da carga de ruptura dos prismas revestidos com adição de tela de aço e que não foi observada nos prismas com revestimento $\mathrm{e}$ sem tela. Esse comportamento mais regular pode ser atribuído exclusivamente à tela. É possível inferir que o revestimento com a argamassa armada deve ter contribuído para a capacidade de carga dos prismas desde o início do processo de carga, mas sua participação mais efetiva se deu quando os blocos não tinham mais capacidade de suportar o carregamento aplicado.

Quando se adicionou a tela de aço no interior da argamassa, observou-se um incremento na capacidade de carga do prisma revestido de aproximadamente $27 \%$, para o caso de tela galvanizada, e de $51 \%$, para o caso de tela eletrossoldada. Esse melhor desempenho da tela eletrossoldada pode ser atribuído às melhores condições de aderência.

A capa de revestimento contribuiu de maneira importante para o aumento da carga de ruptura dos prismas. $\mathrm{O}$ incremento obtido com a colocação da malha de aço no interior da argamassa de revestimento também proporcionou uma melhora significativa na capacidade de carga dos prismas estudados em torno de $65 \%$. A Tabela 8 apresenta uma comparação dos resultados dos prismas de blocos de concreto e blocos cerâmicos.

Analisando a Tabela 7, pode-se perceber que a influência do revestimento no bloco cerâmico foi maior que no bloco de concreto. A malha de aço imersa na camada de revestimento exibiu maior influência na capacidade de carga dos prismas de blocos de concreto do que nos prismas de blocos cerâmicos. Com feito, um incremento de mais de $50 \%$ foi observado na carga média de ruptura dos prismas de blocos de concreto ao passo que nos prismas de blocos cerâmicos o incremento observado foi de $30,88 \%$.

No decorrer dos ensaios foi possível observar que os blocos cerâmicos entravam em colapso muito antes de o prisma atingir a carga de ruptura e, em decorrência, a argamassa de revestimento era muito mais solicitada. A menor contribuição da tela de aço para o aumento na capacidade de carga dos prismas de blocos cerâmicos pode ser explicada pelo fato de esta entrar em processo de flambagem quando atingida uma carga crítica, levando consigo a camada de revestimento.

A ação dos conectores se mostrou fundamental por combaterem os esforços transversais de tração que motivam a ruptura e pelo fornecimento de alguma ductilidade ao conjunto. Para os blocos de concreto, a flambagem das telas foi combatida parcialmente pelos conectores que interligam as duas malhas de aço imersas nas capas de revestimento.

\section{Súmulas dos resultados dos prismas de blocos de concreto e de blocos cerâmicos ensaiados}

Tomando como base a capacidade de carga dos modelos estudados, os resultados dos ensaios experimentais realizados em prismas de blocos cerâmicos e de concreto, as seguintes conclusões podem ser extraídas.

Tabela 7 - Comparação entre as cargas médias de ruptura dos prismas de blocos de concreto e blocos cerâmicos

\begin{tabular}{l|c|c}
\hline \multicolumn{1}{c|}{ Indicador de comparação } & \multicolumn{2}{c}{ Tipo de blocos } \\
\cline { 2 - 3 } & Concreto & Cerâmico \\
\hline Incremento de carga após a aplicação da argamassa & $71,91 \%$ & $130,84 \%$ \\
Incremento de carga após a aplicação dos conectores à malha de aço & $69,81 \%$ & - \\
Incremento de carga após a aplicação da malha de aço sem conectores & $50,74 \%$ & $30,88 \%$ \\
Incremento de carga após reforço de argamassa armada com conectores & $164,76 \%$ & $174,18 \%$ \\
\hline
\end{tabular}




\section{Blocos cerâmicos}

(a) os ensaios realizados indicaram que os revestimentos contribuíram para aumentar a capacidade de carga vertical dos prismas estudados;

(b) o incremento observado na carga média de ruptura, decorrente exclusivamente da incorporação de camada de revestimento, foi de $130 \%$;

(c) vários tipos de ruptura foram observados, de modo que não é possível eleger uma forma de ruptura típica. Por outro lado, foram frequentes as rupturas por deslocamento lateral excessivo da capa de revestimento decorrente da mudança do estado de tensão da argamassa de assentamento em virtude do quadro de fissuração excessivo dos septos dos blocos; e

(d) o incremento obtido com a colocação da malha de aço no interior da argamassa de revestimento foi de $31 \%$ e $24 \%$, para tela eletrossoldada e tela galvanizada, respectivamente, evidenciando a importante participação das telas no interior da argamassa de revestimento.

\section{Blocos de concreto}

(a) os ensaios realizados indicaram que os revestimentos contribuíram para aumentar a capacidade de carga vertical dos prismas estudados;

(b) esse aumento na carga média de ruptura alcançou $72 \%$ nos prismas com revestimento sem tela, $117 \%$ nos modelos com tela de aço galvanizados e $159 \%$ nos modelos com tela eletrossoldada;

(c) a colocação da tela de aço galvanizado no interior da argamassa do revestimento contribuiu para um incremento de $23 \%$ na carga média de ruptura do prisma; (d) a colocação da tela de aço eletrossoldada no interior da argamassa do revestimento contribuiu para um incremento de $50 \%$ na carga média de ruptura do prisma;

(e) a existência da tela de aço no interior da argamassa de revestimento contribui para um melhor desempenho dos modelos estudados, notadamente na uniformização da carga média de ruptura dos blocos;

(f) os prismas de bloco de concreto apresentam um incremento da carga média de ruptura de mais de 300\% referente à aplicação de uma camada de argamassa armada com malha de aço sobre uma camada de argamassa simples existente;

(g) após a aplicação dos conectores ao revestimento dos prismas de concreto observou-se um aumento de aproximadamente $25 \%$ na carga média de ruptura; e

(h) os prismas com $3 \mathrm{~cm}$ de argamassa de revestimento reforçados com malha de aço e conectores apresentaram um acréscimo de mais de 180\% na carga média de ruptura.

\section{Miniparedes}

As Tabelas 8, 9 e 10 exibem as cargas de primeira fissura nos blocos, as cargas de primeira fissura nos revestimentos as cargas de ruptura das miniparedes ensaiadas, destacando os valores da média, desvio padrão e coeficiente de variação para cada tipo.

A ruptura da maioria das miniparedes se deu no septo dos blocos na região superior, próximo do ponto de aplicação da carga, sendo posteriormente acompanhadas de fissuras na interface revestimento/chapisco. A Figura 19 mostra detalhes da forma de ruptura característica das miniparedes revestidas.

Tabela 8 - Cargas de primeira fissura nos blocos

\begin{tabular}{|c|c|c|c|c|}
\hline \multirow[b]{2}{*}{ Miniparede } & \multirow{2}{*}{$\begin{array}{c}\text { Carga } \\
\text { média de } \\
1^{\mathrm{a}} \text { fissura } \\
(\mathrm{kN}) \\
\end{array}$} & \multicolumn{2}{|c|}{ Medidas de dispersão } & \multirow{2}{*}{$\begin{array}{c}\text { Carga } \\
\text { característica } \\
\text { de } 1^{\mathrm{a}} \text { fissura } \\
(\mathrm{kN})\end{array}$} \\
\hline & & $\begin{array}{c}\text { Desvio } \\
\text { padrão } \\
(\mathbf{k N})\end{array}$ & $\begin{array}{c}\text { COV } \\
(\%)\end{array}$ & \\
\hline Sem revestimento & 41,40 & 11,60 & 27,90 & 22,30 \\
\hline Com chapisco & 67,90 & 19,60 & 28,80 & 35,60 \\
\hline Rev: $1: 2: 9$, esp. $1,5 \mathrm{~cm}$ & 85,30 & 22,70 & 26,60 & 47,80 \\
\hline Rev: 1:2:9, esp. 3,0 cm & 96,10 & 34,50 & 35,90 & 39,20 \\
\hline Rev: $1: 1: 6$, esp. $3,0 \mathrm{~cm}$ & 105,50 & 43,40 & 41,10 & 33,90 \\
\hline Rev: $1: 0,5: 4,5$, esp. $3,0 \mathrm{~cm}$ & 170,30 & 54,20 & 31,80 & 80,90 \\
\hline Rev: $1: 2: 9$, esp. $1,5 \mathrm{~cm}+$ Ref $1: 1: 6$ esp $3,0 \mathrm{~cm}$ e tela & 242,00 & 84,60 & 35,00 & 102,40 \\
\hline Rev: $1: 2: 9$ esp. $3,0 \mathrm{~cm}+\operatorname{Ref} 1: 1: 6$, esp $3,0 \mathrm{~cm}$ e tela & 254,80 & 57,50 & 22,60 & 159,90 \\
\hline
\end{tabular}

190 Oliveira, R. A.; Silva, F. A. N.; Pires Sobrinho, C. W. de A.; Azevedo, A. A. C. de 
Tabela 9 - Cargas de primeira fissura no revestimento

\begin{tabular}{|c|c|c|c|c|}
\hline \multirow[b]{2}{*}{ Miniparede } & \multirow{2}{*}{$\begin{array}{c}\text { Carga } \\
\text { média de } \\
1^{\mathrm{a}} \text { fissura } \\
(\mathrm{kN})\end{array}$} & \multicolumn{2}{|c|}{ Medidas de dispersão } & \multirow{2}{*}{$\begin{array}{c}\text { Carga } \\
\text { característica } \\
\text { de } 1^{\text {a fissura }} \\
(\mathbf{k N}) \\
\end{array}$} \\
\hline & & $\begin{array}{c}\text { Desvio } \\
\text { padrão } \\
(\mathbf{k N})\end{array}$ & $\operatorname{COV}(\%)$ & \\
\hline Sem revestimento & - & - & - & - \\
\hline Com chapisco & - & - & - & - \\
\hline Rev: $1: 2: 9$, esp. $1,5 \mathrm{~cm}$ & - & - & - & - \\
\hline Rev: $1: 2: 9$, esp. $3,0 \mathrm{~cm}$ & 123,70 & 34,00 & 27,50 & 67,60 \\
\hline Rev: $1: 1: 6$, esp. $3,0 \mathrm{~cm}$ & 133,10 & 48,70 & 36,30 & 52,70 \\
\hline Rev: $1: 0,5: 4,5$, esp. $3,0 \mathrm{~cm}$ & 240,80 & 42,60 & 17,70 & 170,50 \\
\hline Rev: $1: 2: 9$, esp. $1,5 \mathrm{~cm}+\operatorname{Ref} 1: 1: 6$, esp. $3,0 \mathrm{~cm}$ e tela & 252,10 & 44,90 & 17,80 & 178,00 \\
\hline Rev: $1: 2: 9$, esp. 3,0 cm + Ref $1: 1: 6$, esp. $3,0 \mathrm{~cm}$ e tela & 206,60 & 59,70 & 28,80 & 108,10 \\
\hline
\end{tabular}

Tabela 10 - Carga média de ruptura das miniparedes

\begin{tabular}{|c|c|c|c|c|}
\hline \multirow[b]{2}{*}{ Miniparede } & \multirow{2}{*}{$\begin{array}{c}\text { Carga } \\
\text { média de } \\
\text { ruptura } \\
(\mathrm{kN})\end{array}$} & \multicolumn{2}{|c|}{ Medidas de dispersão } & \multirow{2}{*}{$\begin{array}{c}\text { Carga } \\
\text { característica } \\
\text { de ruptura } \\
(\mathbf{k N})\end{array}$} \\
\hline & & $\begin{array}{c}\text { Desvio } \\
\text { padrão } \\
(\mathbf{k N})\end{array}$ & $\begin{array}{c}\text { COV } \\
(\%)\end{array}$ & \\
\hline Sem revestimento & 56,30 & 8,70 & 15,40 & 41,90 \\
\hline Com chapisco & 84,90 & 16,30 & 19,20 & 58,00 \\
\hline Rev: $1: 2: 9$, esp. $1,5 \mathrm{~cm}$ & 130,40 & 24,40 & 18,70 & 90,10 \\
\hline Rev: $1: 2: 9$, esp. $3,0 \mathrm{~cm}$ & 156,50 & 16,10 & 10,30 & 129,90 \\
\hline Rev: $1: 1: 6$, esp. $3,0 \mathrm{~cm}$ & 168,30 & 33,30 & 19,80 & 113,40 \\
\hline Rev: $1: 0,5: 4,5$, esp. $3,0 \mathrm{~cm}$ & 262,20 & 42,70 & 16,30 & 191,70 \\
\hline Rev: $1: 2: 9$, esp. $1,5 \mathrm{~cm}+\operatorname{Ref} 1: 1: 6$, esp. $3,0 \mathrm{~cm}$ e tela & 321,00 & 47,70 & 14,90 & 242,30 \\
\hline Rev: $1: 2: 9$, esp. $3,0 \mathrm{~cm}+$ Ref $1: 1: 6$, esp. 3,0 cm e tela & 367,00 & 49,30 & 13,40 & 285,70 \\
\hline Rev: $1: 1: 6$, esp. $3,0 \mathrm{~cm}+\operatorname{Ref} 1: 1: 6$, esp. 3,0 cm e tela & 417,09 & 62,99 & 15,10 & 313,35 \\
\hline
\end{tabular}

Figura 19 - Forma de ruptura das miniparedes revestidas com argamassa

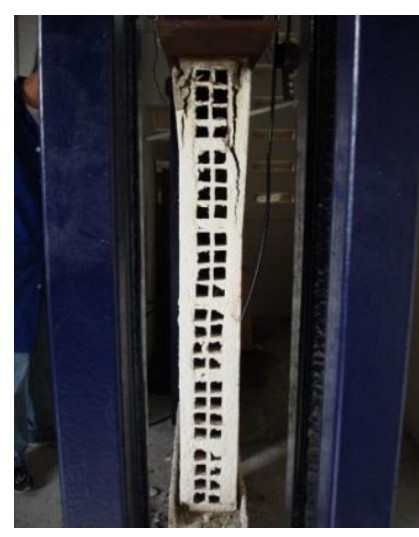

Esse comportamento é decorrente do estado de solicitação triaxial a que a argamassa de assentamento está submetida, consequência do seu confinamento entre os blocos. Esse estado de solicitação gera tensões horizontais de tração que surgem devido à aderência mobilizada entre a argamassa e os blocos que solicitam seus septos horizontais. Assim, no momento em que a tensão ultrapassa a resistência à tração desses septos, eles fissuram, transmitindo esse esforço para os demais e para o revestimento que tende a fissurar ou

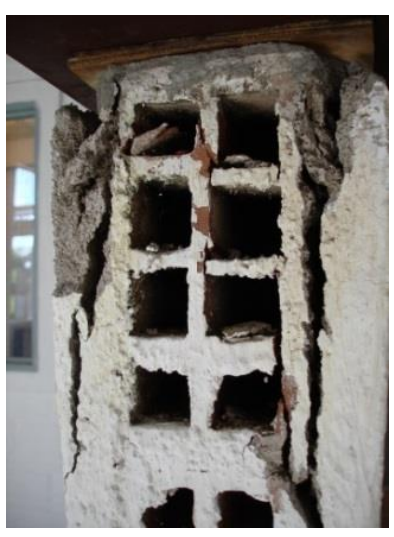

destacar, se não houver aderência satisfatória, antes da ruptura da parede.

Nos casos das miniparedes sem reforço com tela, as fissuras nos septos dos blocos aconteceram antes de serem observadas fissuras na argamassa de revestimento, o que indica uma participação efetiva do revestimento no comportamento compressivo da miniparede.

No caso do reforço com telas e conectores, a fissura inicial foi observada na interface entre argamassa de revestimento e argamassa de reforço. 
Isto ocorreu possivelmente pela maior deformabilidade da capa de argamassa armada e de seu posicionamento (sem confinamento) em relação ao núcleo da alvenaria revestida e confinada e a menor aderência na interface entre o revestimento antigo e o novo.

Da análise comparativa dos resultados podem ser feitas as considerações que se seguem.

\section{Influência do chapisco}

Foi observado que a simples aplicação do chapisco, com espessura de $5 \mathrm{~mm}$, gerou um acréscimo médio de $50,7 \%$ na carga de ruptura das miniparedes, sem, no entanto, alterar a forma brusca de colapso.

Analisando o comportamento das miniparedes ensaiadas (Figuras 20 e 21), foi possível observar um aumento da inclinação da curva carga $\mathrm{x}$ deslocamento. A rigidez média das miniparedes sem chapisco foi da ordem de $17,28 \mathrm{kN} / \mathrm{m}$, enquanto as miniparedes com chapisco foi de $21,60 \mathrm{kN} / \mathrm{m}$, o que representa um aumento de $25 \%$. Neste gráfico, os trechos das curvas cargadeslocamento situados após os valores das cargas máximas representam a curva de descarregamento da prensa e não têm significado físico.

Figura 20 - Diagrama carga x deslocamento das miniparedes sem chapisco

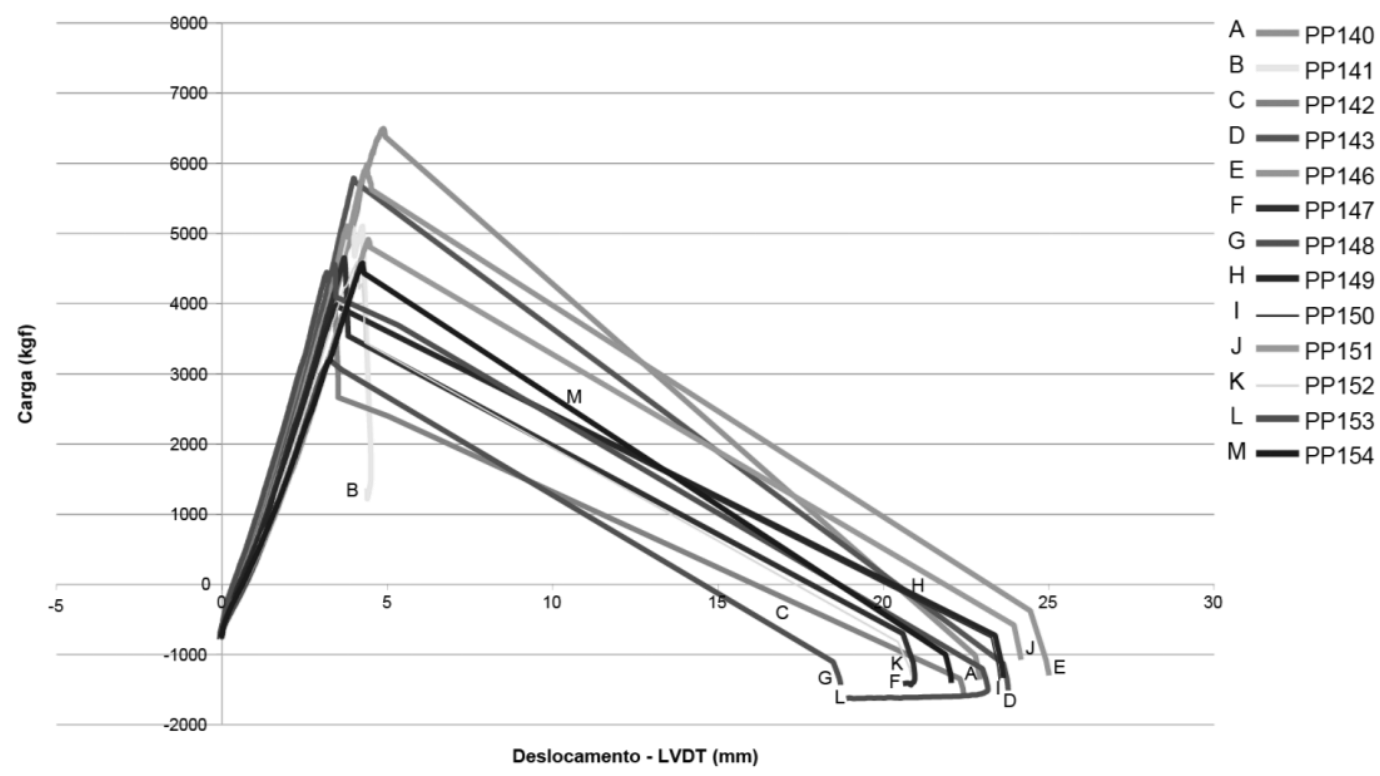

Figura 21 - Diagrama carga $x$ deslocamento das miniparedes com chapisco

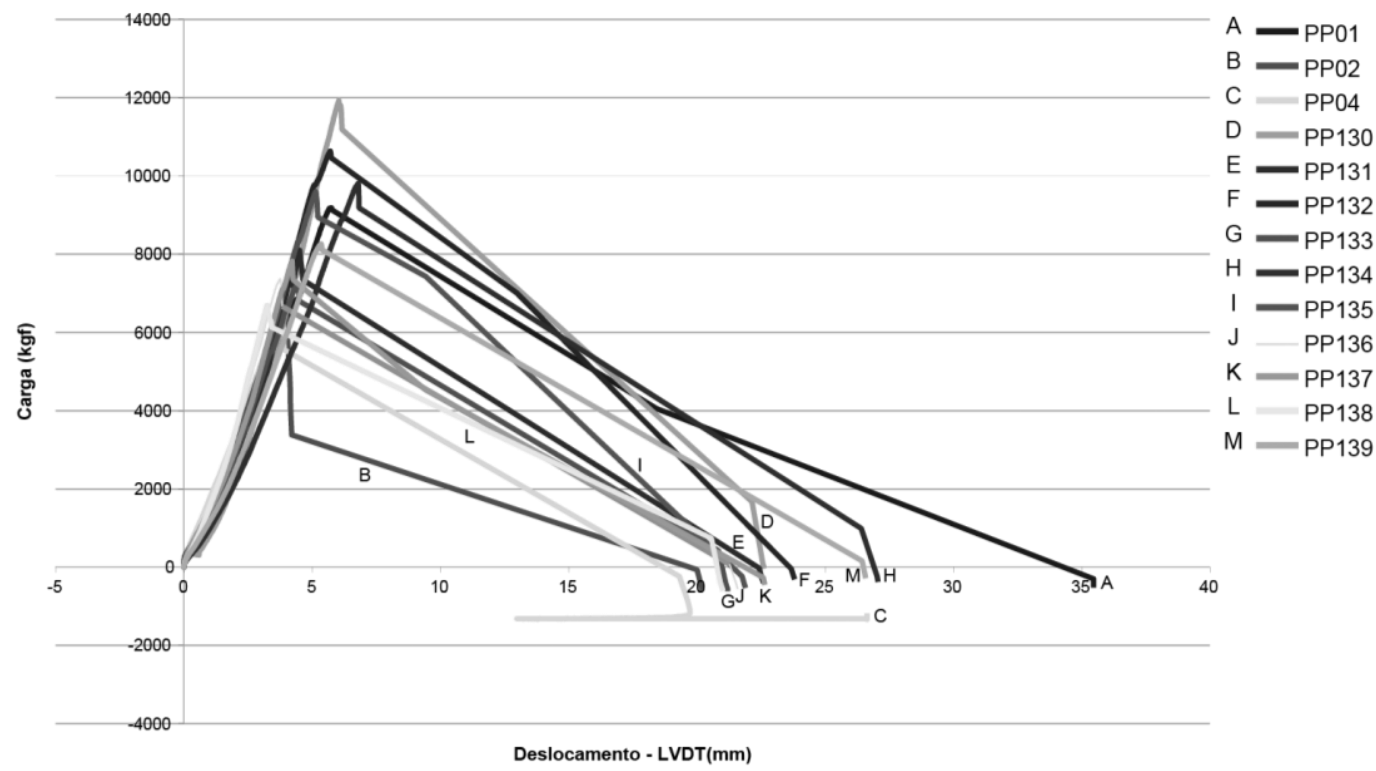

192 Oliveira, R. A.; Silva, F. A. N.; Pires Sobrinho, C. W. de A.; Azevedo, A. A. C. de 
Os resultados mostram que a camada de chapisco gerou um incremento de $50 \%$ na capacidade de carga da miniparede e um aumento de $25 \%$ em sua rigidez sem, no entanto, alterar a forma de ruptura brusca da alvenaria.

\section{Influência do traço da argamassa de revestimento}

Procedendo-se a uma análise comparativa dos resultados em miniparedes revestidas com $3,0 \mathrm{~cm}$ de argamassa de diferentes traços, 1:2:9, 1:1:6 e 1:0,5:4,5, foi possível observar um discreto aumento na capacidade de carga das miniparedes, da ordem de 7,5\%, entre a argamassa de traço 1:2:9 e 1:1:6, e um considerável aumento, da ordem de $55,8 \%$, entre a argamassa de traço $1: 0,5: 4,5$ e $1: 1: 6$.

Analisando o comportamento compressivo das miniparedes ensaiadas (Figura 22 a 24) é possível observar que há um aumento da rigidez das miniparedes revestidas com o aumento da dosagem de cimento na argamassa. As miniparedes revestidas com argamassa de traço 1:2:9 apresentou rigidez média da ordem de $48 \mathrm{kN} / \mathrm{m}$, as revestidas com argamassa no traço 1:1:6 apresentou rigidez média da ordem de $58 \mathrm{kN} / \mathrm{m}$, acréscimo da ordem de $21 \%$. Já a revestida com argamassa no traço 1:0,5:4,5 apresentou rigidez média da ordem de $64 \mathrm{kN} / \mathrm{m}$, o que representa um acréscimo de $10 \%$ em relação à anterior. Neste gráfico, os trechos das curvas carga-deslocamento situados após os valores das cargas máximas representam a curva de descarregamento da prensa e não têm significado físico.

O aumento da quantidade de cimento das argamassas de revestimento produz um aumento da capacidade de carga e da rigidez das alvenarias, sem, no entanto, alterar a forma de ruptura brusca das alvenarias revestidas.

\section{Influência da espessura do revestimento}

Promovendo-se uma análise comparativa da resistência média em função da espessura das miniparedes revestidas no traço 1:2:9, nas espessuras $1,5 \mathrm{~cm} \mathrm{e} 3,0 \mathrm{~cm}$, pode ser observado que a carga de ruptura cresceu com o aumento da espessura. É possível observar que esse aumento foi da ordem de $8,5 \%$, entre a espessura de $1,5 \mathrm{~cm}$ e a de $3,0 \mathrm{~cm}$. Os incrementos na carga de ruptura em relação às paredes revestidas apenas com chapisco foram de $58 \%$ e $72 \%$, respectivamente.

\section{Influência do reforço com argamassa e tela de aço}

Miniparedes revestidas com 3,0 cm de espessura nos traços 1:2:9 e 1:1:6 foram reforçadas com telas de aço em malha de $(10 \mathrm{~cm} \mathrm{x} 10 \mathrm{~cm})$ e fios de diâmetro $4,2 \mathrm{~mm}$, travadas com barras de aço de $6.0 \mathrm{~mm}$ a cada $20 \mathrm{~cm}$ de espaçamento e revestidas com argamassa no traço 1:1:6.

Figura 22 - Diagrama carga $x$ deslocamento das miniparedes revestidas com $3,0 \mathrm{~cm}$ de argamassa no traço $1: 2: 9$

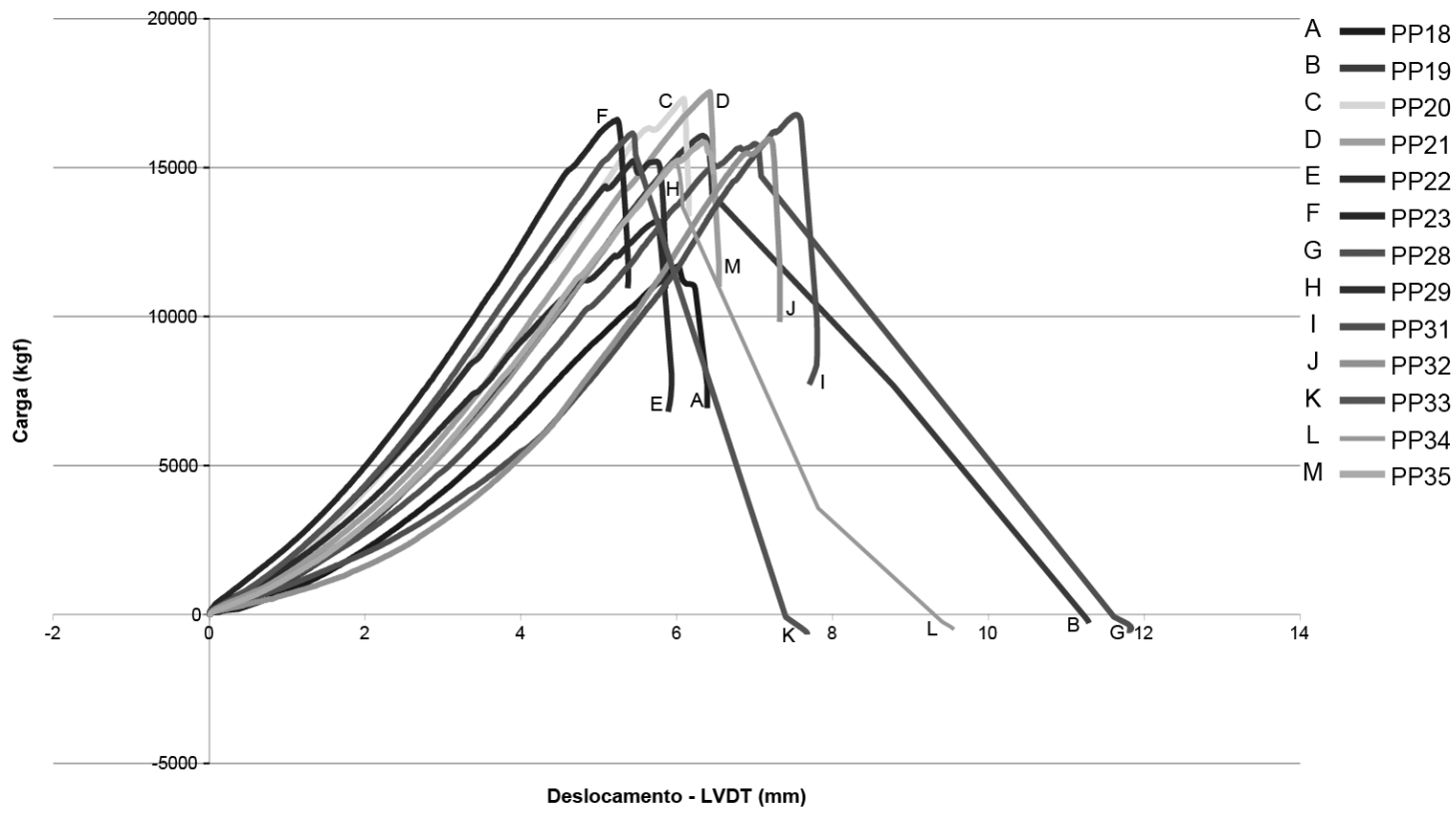


Figura 23 - Diagrama carga x deslocamento das miniparedes revestidas com $3,0 \mathrm{~cm}$ de argamassa no traço 1:1:6

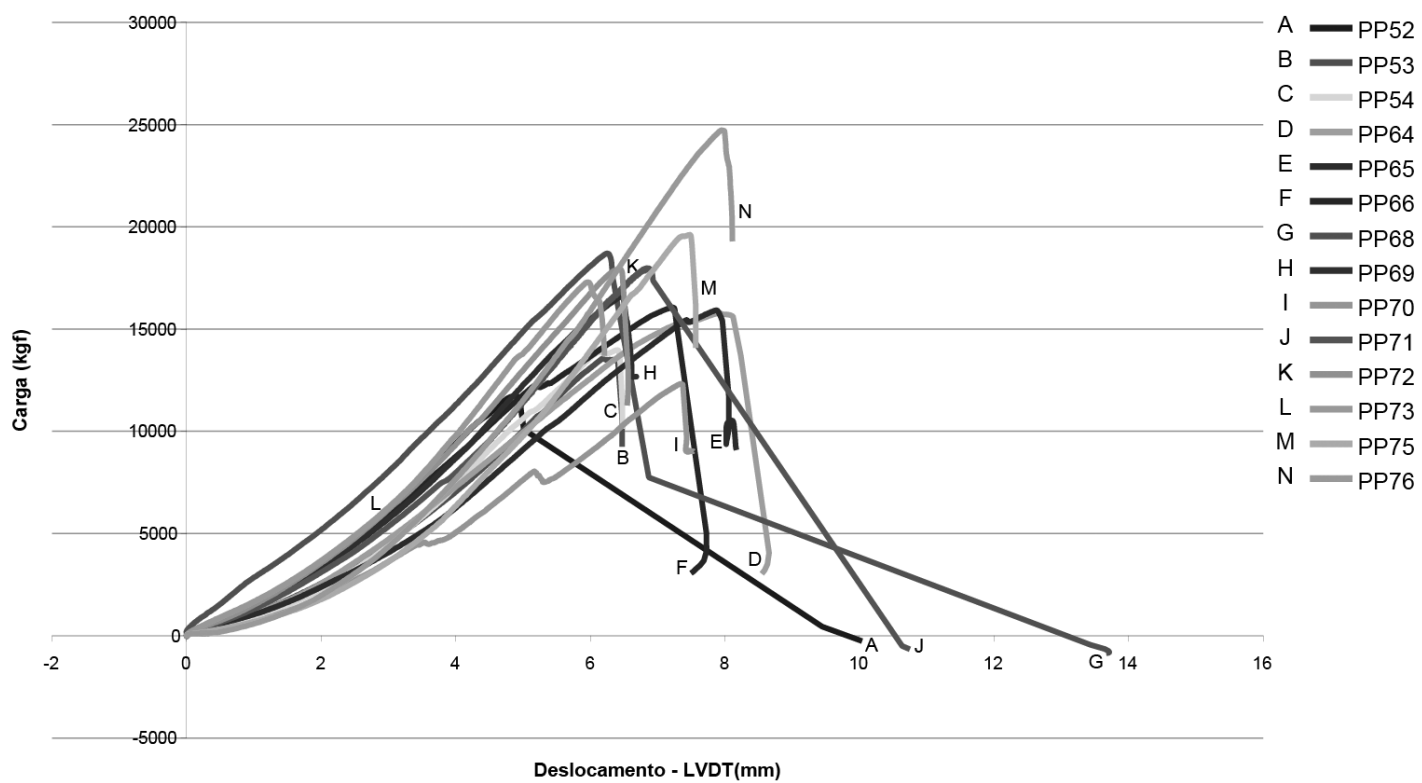

Figura 24 - Diagrama carga $x$ deslocamento das miniparedes revestidas com 3,0 cm de argamassa no traço $1: 0,5: 4,5$

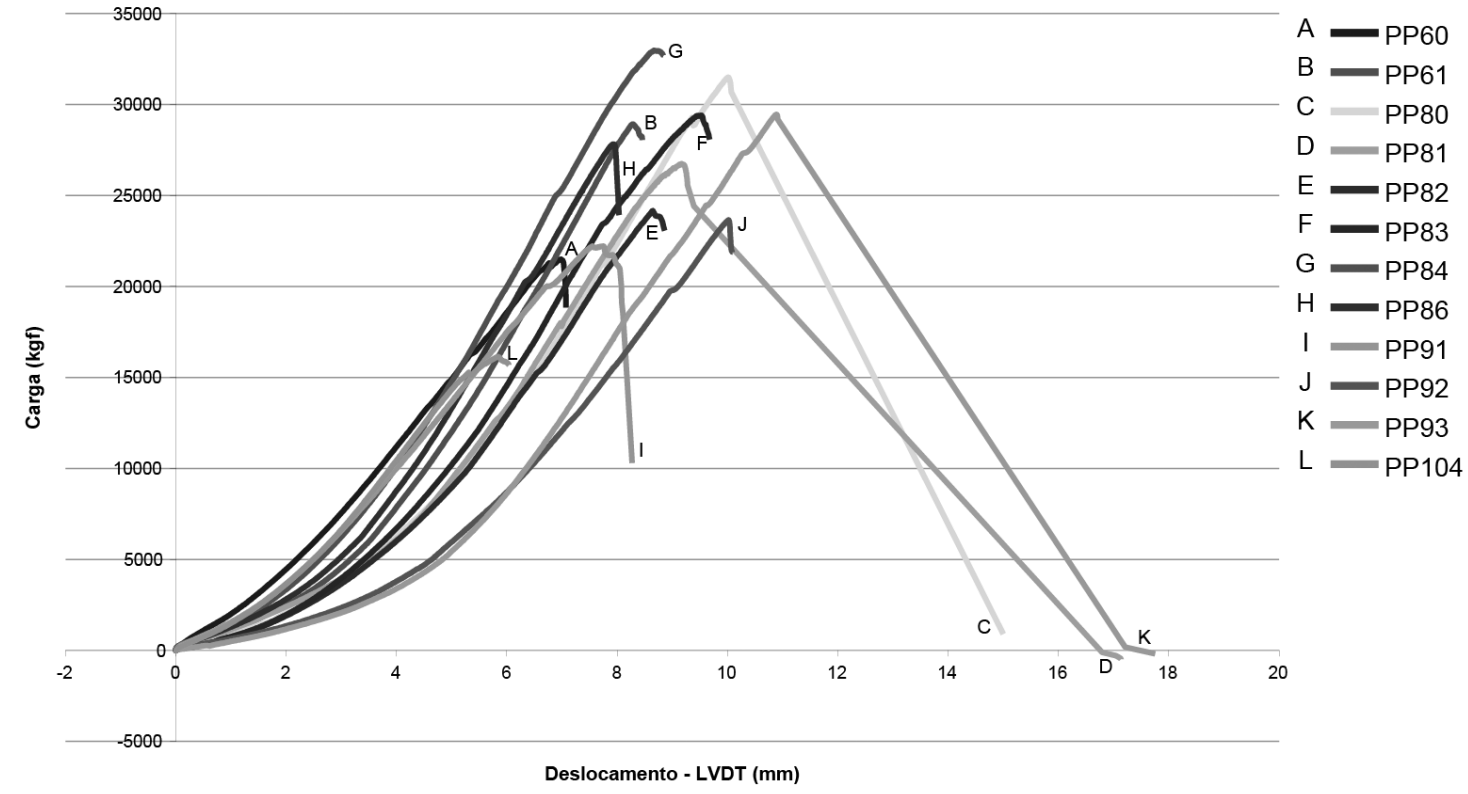

Os resultados mostram um expressivo incremento na capacidade de carga das miniparedes, quando reforçadas com telas de aço intertravadas por conectores. Aumentos de $134,50 \%$ e $147,82 \%$ foram observados nas miniparedes com argamassa de revestimento no traço 1:2:9 e 1:1:6, respectivamente.
As Figuras 25 a 28 a seguir exibem as curvas típicas força $\mathrm{x}$ deslocamento das diversas tipologias de miniparedes ensaiadas. Neste gráfico, os trechos das curvas carga-deslocamento situados após os valores das cargas máximas representam a curva de descarregamento da prensa e não têm significado físico. 
Figura 25 - Diagrama carga x deslocamento das miniparedes - revestimento 1:2:9, espessura de $3,0 \mathrm{~cm}$ sem reforço

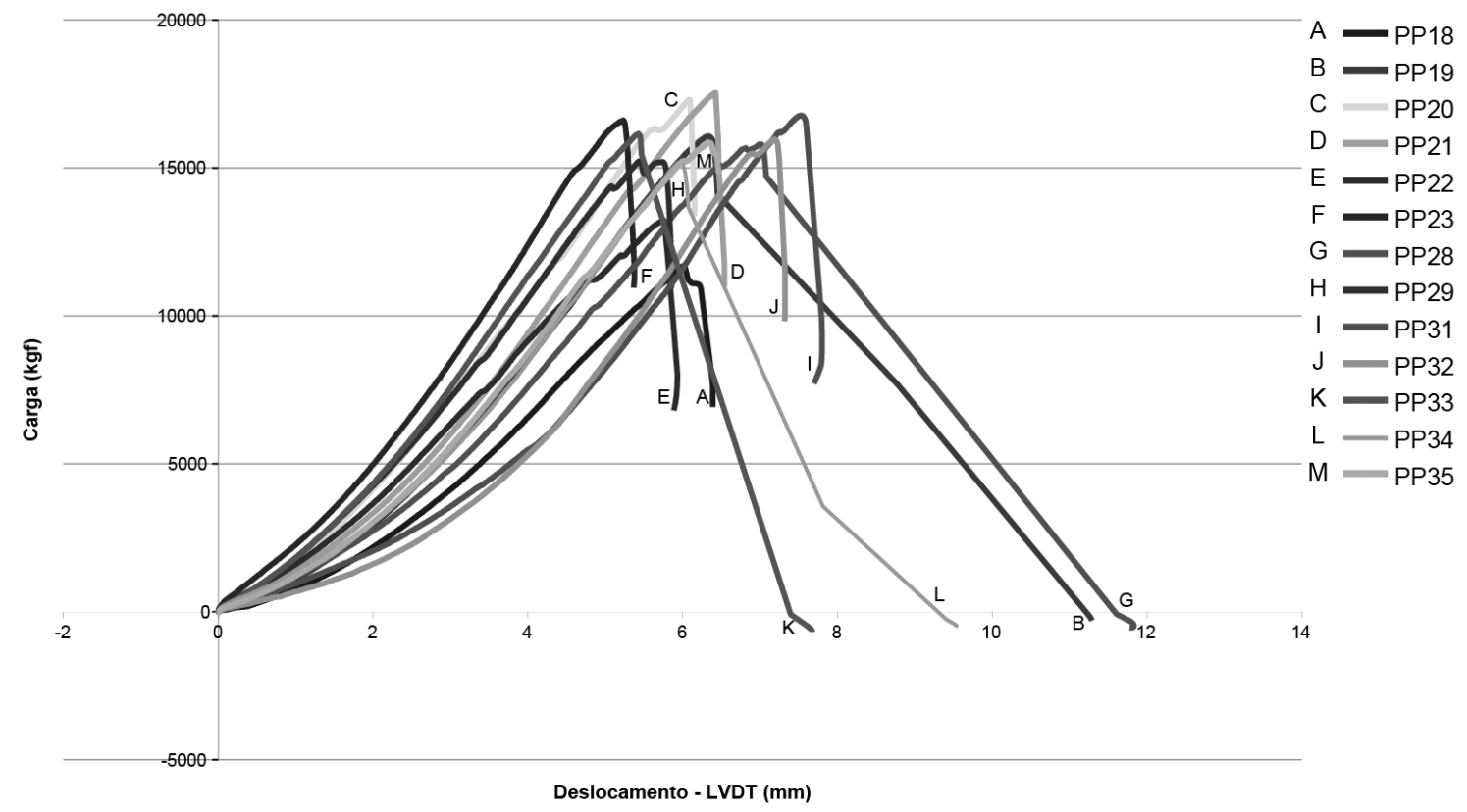

Figura 26 - Diagrama carga $x$ deslocamento das miniparedes - revestimento 1:2:9, espessura de $3,0 \mathrm{~cm}$ com reforço tela $4.2 \mathrm{~mm}$ \#10 cm +1:1:6 esp. 3,0 cm

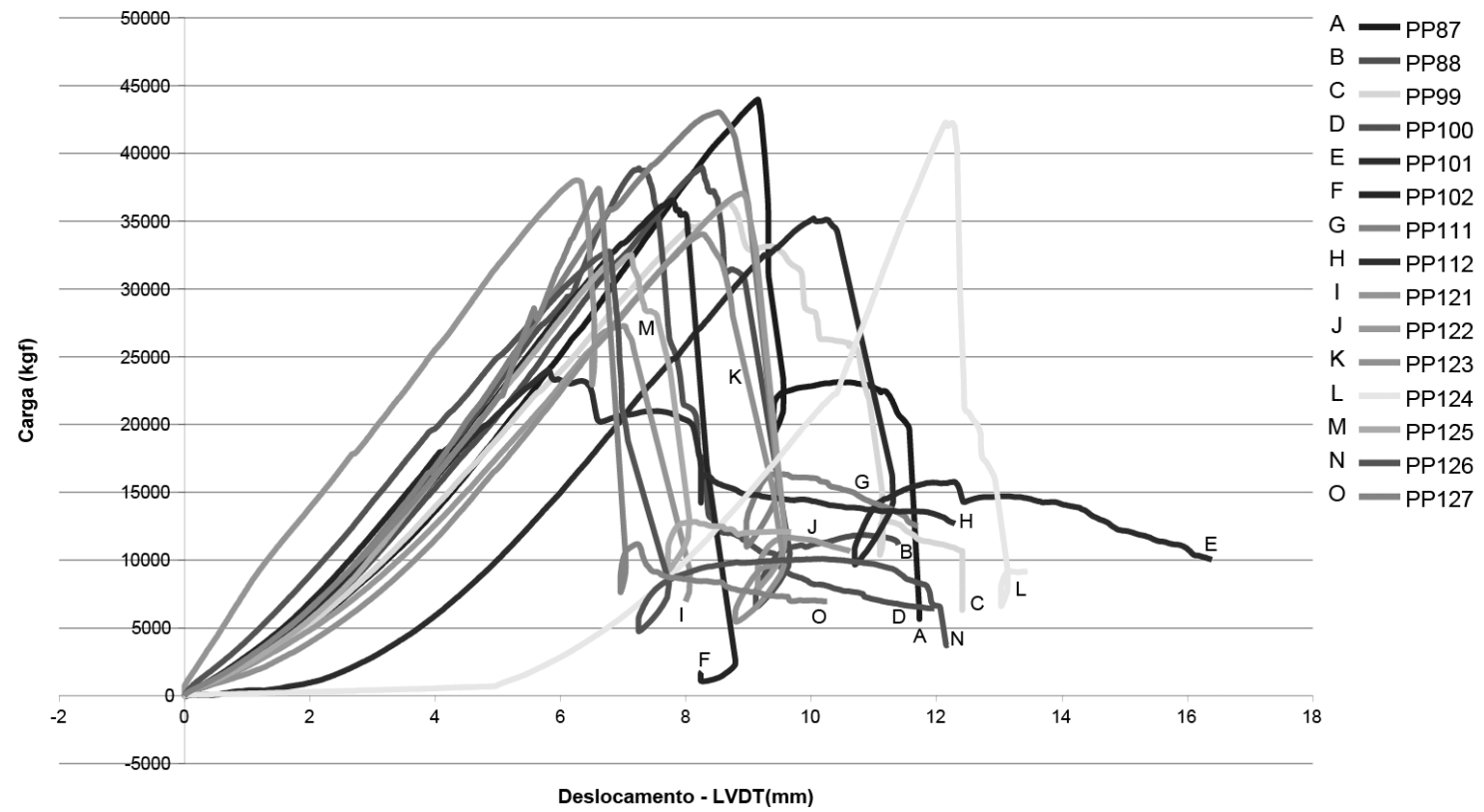


Figura 27 - Diagrama carga x deslocamento das miniparedes - revestimento 1:1:6, espessura de $3,0 \mathrm{~cm}$ sem reforço

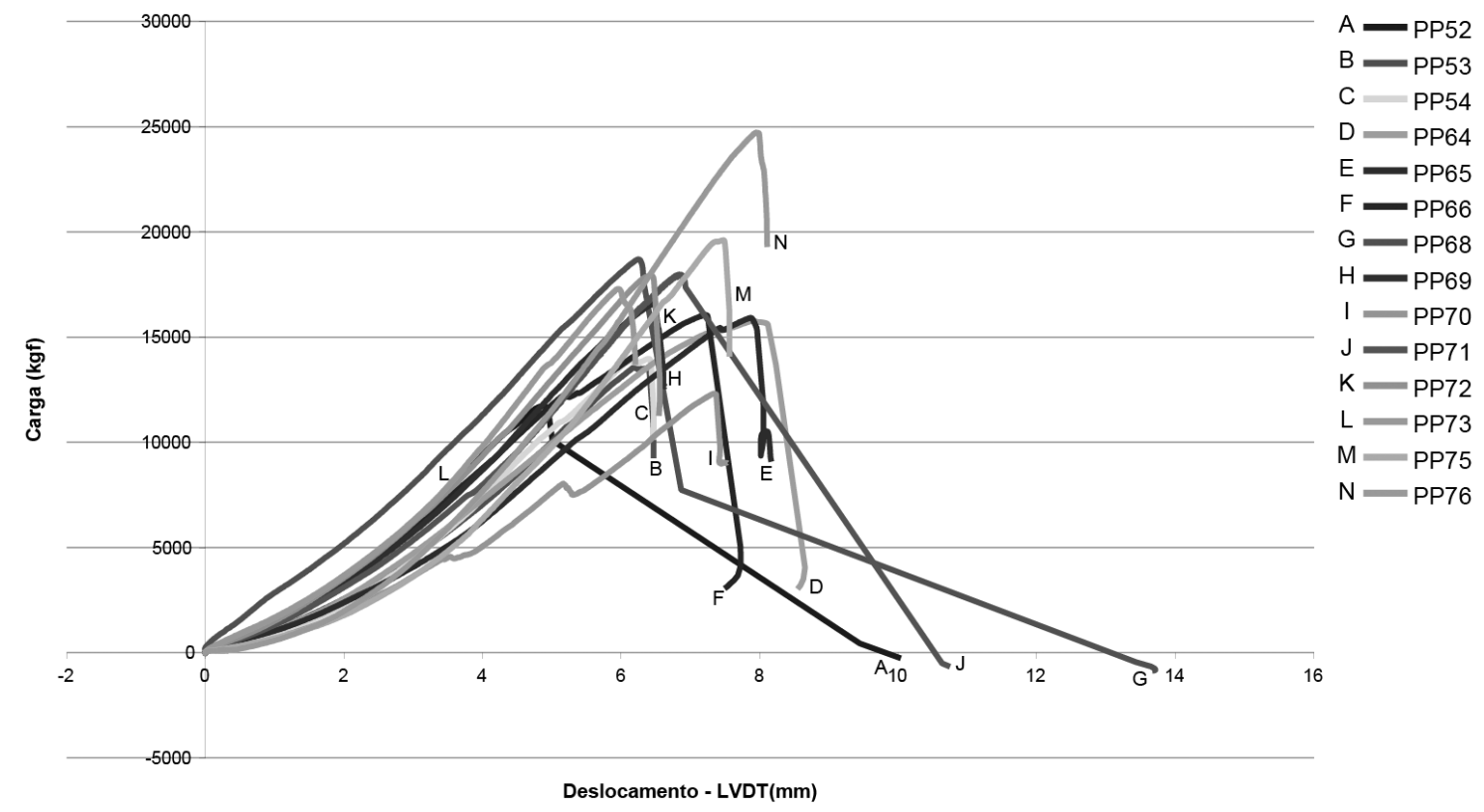

Figura 28 - Diagrama carga $x$ deslocamento das miniparedes - revestimento 1:1:6, espessura de $3,0 \mathrm{~cm}$ com reforço tela $4.2 \mathrm{~mm}$, \#10 cm +1:1:6, esp. $3,0 \mathrm{~cm}$

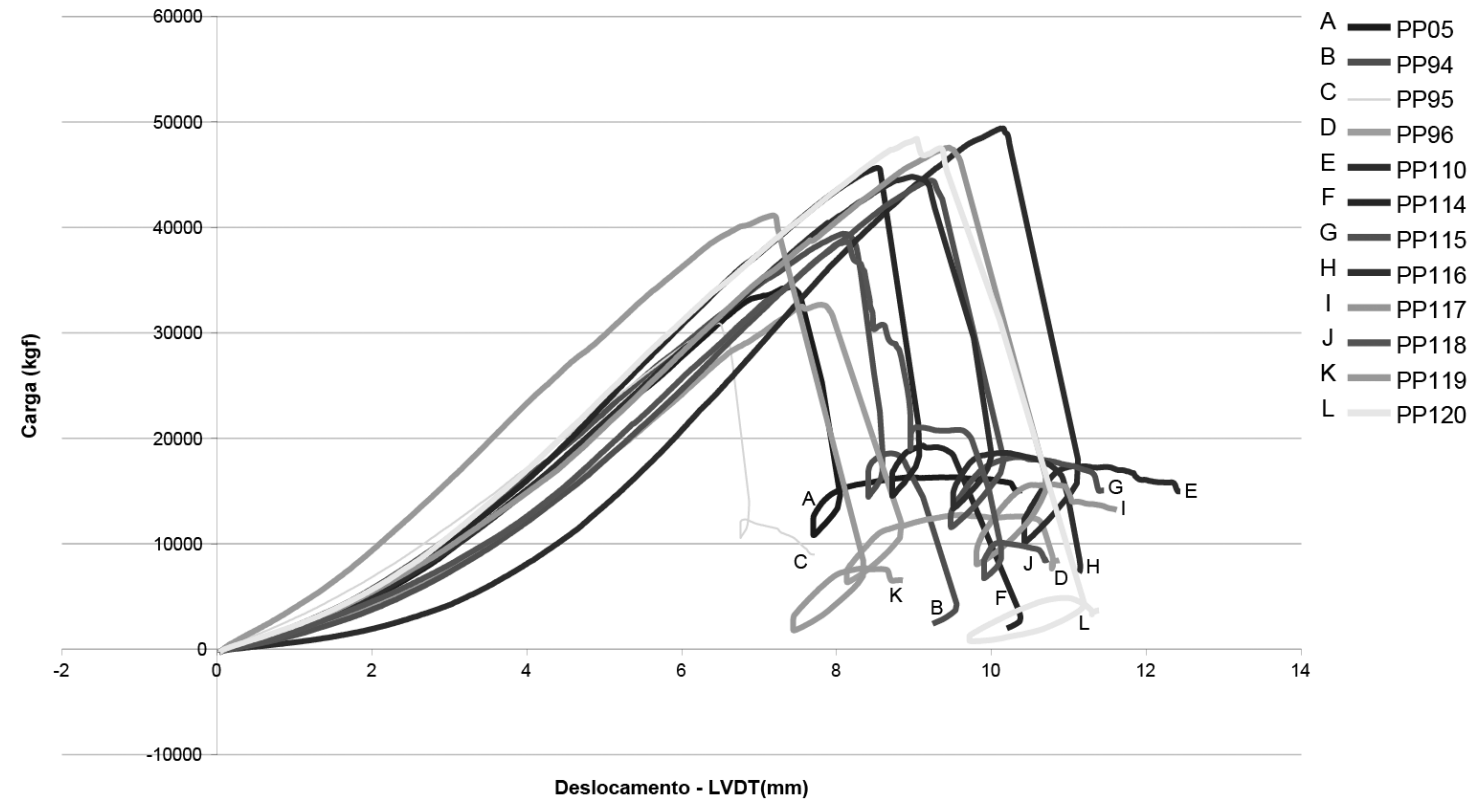

Observando-se o comportamento pós-ruptura das miniparedes reforçadas com tela nota-se a importância dos conectores entre telas. Enquanto os ganchos dos conectores dobrados a $90^{\circ}$ não abriram as miniparedes mantiveram uma capacidade resistente da ordem das paredes sem reforço.

\section{Súmula dos resultados das miniparedes ensaiadas}

O revestimento em argamassa nas paredes de alvenaria produziu um aumento da capacidade resistente e da rigidez das paredes, e esse incremento é crescente com a espessura e o maior consumo de cimento da argamassa. 
A incorporação de revestimento em argamassa não alterou a forma de ruptura das alvenarias, que acontece de forma brusca, porém foi constatado que há uma efetiva participação do revestimento no comportamento compressivo de paredes.

O reforço com telas e conectores, além de elevar a capacidade resistente das paredes, produziu mudança significativa nas suas formas de ruptura. As miniparedes reforçadas com tela, embora tenham apresentado ruptura brusca, não colapsaram, mostrando certa reserva de resistência.

Os conectores exercem papel fundamental no comportamento compressivo das miniparedes ensaiadas, a exemplo do que ocorreu com os prismas.

Há de se considerar que os incrementos de resistências expressos em percentuais dependem da resistência dos blocos empregados. Para blocos de resistências inferiores os incrementos serão maiores, enquanto para blocos de resistências superiores ocorre o contrário.

\section{Conclusões}

Ao longo da pesquisa foram ensaiados mais de 500 prismas constituídos de blocos de concreto e de blocos cerâmicos, 154 miniparedes de blocos cerâmicos. Os ensaios realizados permitem as seguintes considerações:

(a) a capa de revestimento contribuiu para o aumento da capacidade de carga dos modelos ensaiados (prismas e miniparedes);

(b) a incorporação de telas de aço intertravadas por conectores de aço concorreu para um incremento adicional de carga. $\mathrm{O}$ conector demonstrou desempenhar papel fundamental no incremento da capacidade de carga dos prismas e miniparedes revestidos com argamassa e tela, sem conectores; e

(c) variadas formas de ruptura dos prismas e miniparedes ensaiados foram observadas, de modo que não se pode eleger uma única forma como representativa.

Sem prejuízo das considerações anteriormente expostas é importante que sejam observadas as seguintes ressalvas:

(a) a alvenaria resistente não pode ser pensada, em nenhuma hipótese, como um processo construtivo capaz de suportar cargas além de seu peso próprio. Consistentemente com essa afirmação, todos os prédios construídos dentro dessa técnica construtiva devem ser recuperados. Os fatores de risco determinados por qualquer que seja a metodologia devem servir meramente como indicadores da ordem ou sequência em que devem ser recuperados. Fornecem, portanto, apenas uma escala de prioridades para as intervenções a serem efetuadas, que deve ser utilizada com critério pelo gestor do processo de recuperação;

(b) o fato constatado de que a argamassa de revestimento contribui para aumentar a capacidade de carga de uma parede de alvenaria serve meramente para explicar as razões pelas quais a respectiva parede não colapsou. Não autoriza atestar a segurança da edificação que padece de falha congênita, ou seja, ter sido executada com alvenaria de vedação com finalidade estrutural;

(c) os ganhos de resistência observados devem ser utilizados com cautela já que eles serão maiores se a resistência dos blocos utilizados for pequena;

(d) a utilização dos dados e resultados de ensaios da presente pesquisa em soluções específicas de recuperação de edificações em alvenaria resistente é de inteira responsabilidade do projetista, e não cabe aos pesquisadores nenhuma parcela de responsabilidade por esse uso.

\section{Referências}

ANDRADE, S. T. Influência das Características do Revestimento na Resistência à Compressão de Paredinhas de Alvenaria de Blocos Cerâmicos de Vedação. Recife, 2007. Dissertação (Mestrado em Engenharia Civil) - Escola de Engenharia, Universidade Federal de Pernambuco, Recife, 2007.

ARAÚJO NETO, G. N. Influência da Argamassa de Revestimento na Resistência a Compressão Axial de Prismas de Alvenaria Resistente de Blocos de Concreto. Recife, 2006. Dissertação (Mestrado em Engenharia Civil) - Universidade Católica de Pernambuco, Recife, 2006.

\section{ASSOCIAÇÃO BRASILEIRA DE NORMAS}

TÉCNICAS. NBR 15270-1: componentes cerâmicos parte 1: blocos cerâmicos para alvenaria de vedação: terminologia e requisitos. Rio de Janeiro, 2005.

\section{ASSOCIAÇÃO BRASILEIRA DE NORMAS} TÉCNICAS. NBR 15961-1: alvenaria estrutural: blocos de concreto parte 1: projeto. Rio de Janeiro, $2011 b$.

ASSOCIAÇÃO BRASILEIRA DE NORMAS TÉCNICAS. NBR 15961-2: alvenaria estrutural: blocos de concreto parte 2: execução e controle de obras. Rio de Janeiro, 2011a. 
ASSOCIAÇÃO BRASILEIRA DE NORMAS TÉCNICAS. NBR 6136: blocos vazados de concreto simples para alvenaria: requisitos. Rio de Janeiro, 2014.

\section{ASSOCIAÇÃO BRASILEIRA DE NORMAS} TÉCNICAS. NBR 6467: agregados: determinação do inchamento de agregado miúdo: métodos de ensaio. Rio de Janeiro, 2006a.

ASSOCIAÇÃO BRASILEIRA DE NORMAS TÉCNICAS. NBR 7211: agregados para concreto: especificação. Rio de Janeiro, 2009.

ASSOCIAÇÃO BRASILEIRA DE NORMAS TÉCNICAS. NBR 7215: cimento Portland: determinação da resistência à compressão. Rio de Janeiro, 1997.

\section{ASSOCIAÇÃO BRASILEIRA DE NORMAS}

TÉCNICAS. NBR 7219: determinação do teor de materiais pulverulentos nos agregados. Rio de Janeiro, 1982.

\section{ASSOCIAÇÃO BRASILEIRA DE NORMAS}

TÉCNICAS. NBR 7222: concreto e argamassa: determinação da resistência à tração por compressão diametral de corpos de prova cilíndricos. Rio de Janeiro, 2011c.

ASSOCIAÇÃO BRASILEIRA DE NORMAS TÉCNICAS. NBR 9776: argamassa: determinação da massa específica de agregados miúdos por meio do frasco Chapman. Rio de Janeiro, 1998.

\section{ASSOCIAÇÃO BRASILEIRA DE NORMAS} TÉCNICAS. NBR NM 248: determinação da composição granulométrica. Rio de Janeiro, 2003.

ASSOCIAÇÃO BRASILEIRA DE NORMAS TÉCNICAS. NBR NM 45: agregados: determinação da massa unitária e do volume de vazios. Rio de Janeiro, 2006b.

AZEVÊDO, A. A. C. Avaliação Comparativa da Influência do Revestimento Simples e Armado no Comportamento Compressivo de Prismas e Paredinhas de Blocos Cerâmicos de Vedação. Recife, 2010. Dissertação (Mestrado em Engenharia Civil) - Escola de Engenharia, Universidade Católica de Pernambuco, Recife, 2010.

CAMPOS, M. D. Considerações Sobre Soluções Para Recuperação de Prédios Construídos Com Alvenaria Resistente. Recife, 2006. Dissertação (Mestrado em Engenharia Civil) - Escola de Engenharia, Universidade Federal de Pernambuco, Recife, 2006.
HANAI, J. B; OLIVEIRA, F. L. Colapso de Edifícios de Blocos Cerâmicos. Técnhe, v. 115, p. 58-63, 2006.

MOTA, J. M. V. Influência da Argamassa de Revestimento na Resistência à Compressão Axial em Prismas de Alvenaria Resistente de Blocos Cerâmicos. Recife, 2006. Dissertação (Mestrado em Engenharia Civil) - Escola de Engenharia, Universidade Federal de Pernambuco, Recife, 2006.

OLIVEIRA, F. L.; HANAI, J. B. Análise do Comportamento de Paredes de Alvenaria Construídas Com Blocos Cerâmicos de Vedação. In: INTERNATIONAL SEMINAR ON STRUCTURAL MASONRY FOR DEVELOPING COUNTRIES, 7., Belo Horizonte, 2002. Proceedings... Belo Horizonte, 2002.

OLIVEIRA, R. A.; SILVA, F. A. N.; SOBRINHO C. W. Edifícios Construídos com Alvenaria Resistente em Pernambuco: situação atual e perspectivas futuras. In: MONTEIRO, B. S.; VITÓRIO, J. A. P. (Orgs.). O SINAENCO-PE e a Produção do Conhecimento: coletânea de artigos técnicos. Recife: [s.1.], 2008.

OLIVEIRA, R. A.; SILVA, F. A. N.; SOBRINHO, C. W. Alvenaria Resistente: uma investigação experimental e numérica sobre seu comportamento compressivo. Recife: FASA, 2011.

OLIVEIRA, R. A.; SOBRINHO, C. W. Acidentes Com Prédios Construídos Com Alvenaria Resistente na Região Metropolitana do Recife. João Pessoa: DAMSTRUC, 2006.

SOBRINHO, C. W. Metodologia Para a Caracterização de Grau de Risco ao Desabamento de Edificações em Alvenaria Resistente. In: CONGRESSO LATINOAMERICANDO DE PATOLOGIA, 9., Quito, 2007. Anais... Quito, 2007.

\section{Agradecimentos}

Os autores agradecem à Finep e ao $\mathrm{CNPq}$ pelo apoio financeiro concedido através do Edital MCT/Finep/FVA-Habitare n. 02/2004, Convênio n. 01.04.1050.00 - Projeto "Desenvolvimento de Modelo para Recuperação de Edificações em Alvenaria Resistente", que tornou possível a pesquisa da qual este trabalho faz parte. 


\section{Romilde Almeida Oliveira}

Departamento de Engenharia Civil, Centro de Ciências e Tecnologia | Universidade Católica de Pernambuco | Rua do Príncipe, 526, Boa Vista | Recife - PE - Brasil | CEP 50050-900 | Tel.: (81) 2119-4178 | E-mail: romildealmeida@gmail.com

\section{Fernando Artur Nogueira Silva}

Centro de Ciências e Tecnologia | Universidade Católica de Pernambuco | E-mail: farturnog@gmail.com

\section{Carlos Welligton de Azevedo Pires Sobrinho}

Instituto Tecnológico de Pernambuco | Av. Prof. Luís Freire, 700 | Recife - PE - Brasil | CEP 50740-540 | Tel.: (81) 3183-4201 |

E-mail: carlositep@gmail.com

Antônio Augusto Costa de Azevedo

Centro de Ciências e Tecnologia | Universidade Católica de Pernambuco | E-mail: antoni_1184@yahoo.com.br

\section{Revista Ambiente Construído}

Associação Nacional de Tecnologia do Ambiente Construído

Av. Osvaldo Aranha, $99-3^{\circ}$ andar, Centro

Porto Alegre - RS - Brasil

CEP $90035-190$

Telefone: +55 (51) 3308-4084

Fax: +55 (51) 3308-4054

www.seer.ufrgs.br/ambienteconstruido

E-mail: ambienteconstruido@ufrgs.br 